\title{
The Sources of Bile Pigment in the Rat: Studies of the "Early Labeled" Fraction *
}

\author{
Stephen H. Robinson, $†$ Maria Tsong, Barry W. Brown, and \\ RUDI Sch MID \\ (From the Department of Medicine and Biological Sciences Computation Center, University \\ of Chicago, Chicago, Ill., and the Department of Medicine, Beth Israel Hospital and \\ Harvard Medical School, Boston, Mass.)
}

Most of the bile pigment excreted under physiologic conditions is derived from hemoglobin of senescent erythrocytes. However, the classic studies of London, West, Shemin, and Rittenberg (2) and of Gray, Neuberger, and Sneath (3) in 1950 indicated that additional sources account for a small but significant fraction of the total pigment production. With glycine- ${ }^{15} \mathrm{~N}$ as a precursor of hemoglobin heme, it was shown that human erythrocytes containing labeled heme survive for an average of 120 days. As anticipated, most of the labeled bile pigment is formed as these cells leave the circulation and are destroyed. In addition, a smaller fraction of the labeled bile pigment appears within the first few days of isotope administration, when labeled red cells are just beginning to enter the circulation. In normal subjects this "early labeled" pigment (ELP) or "shunt fraction" (4) represents 10 to $20 \%$ of the total bile pigment formed from labeled glycine (2, $3)$. However, in some hematologic disorders, particularly those associated with "ineffective erythropoiesis" (5), the ELP may account for the major portion of the excreted bile pigment $(3,4,6-13)$.

Several recent investigations concerning the origin of the ELP in hematologically normal subjects and experimental animals have yielded con-

\footnotetext{
* Submitted for publication March 14, 1966; accepted June 24, 1966.

Supported in part by U. S. Public Health Service grants AM-07091, AM-09834, FR-00013, and a grant from The Medical Foundation, Inc., Boston, Mass.

Presented in part at the Annual Meeting of the Central Society for Clinical Research, Chicago, Ill., December 6, 1965 (1).

† Formerly Special Research Fellow, National Institutes of Health, U. S. Public Health Service. Address requests for reprints to Dr. Stephen $H$. Robinson, Beth Israel Hospital, Boston, Mass. 02215.
}

flicting results. For example, studies of the role of erythropoiesis have led to the following divergent conclusions : $a$ ) the ELP is significantly increased in response to erythroid stimulation $(14) ; b)$ the ELP is relatively depressed after erythroid stimulation $(15) ; c$ ) red cell hypoplasia is associated with an increased ELP $(10) ; d$ ) red cell hypoplasia results in virtual disappearance of the ELP (13); and $e$ ) only part of the ELP is related to erythropoiesis $(1,16-19)$.

Methodologic difficulties are a major problem in this field and probably account in large part for these discrepancies. Many studies have been based on isotopic assay of fecal stercobilin (2-4, $6-15)$. Kinetic data obtained in this way are of limited significance because of delay in intestinal transit, variable conversion of bilirubin to urobilinogen (20), enterohepatic circulation of bile pigment (21), and individual bowel habit. Hence, it is preferable to assay bilirubin directly in the bile or plasma. However, the former requires external biliary drainage, precluding prolonged studies under physiologic conditions, and the latter necessitates radioassay of plasma bilirubin, which normally is of low concentration. Moreover, the very rapid turnover of bilirubin in normal subjects may preclude adequate mixing in the plasma of labeled pigment produced from different sources. Finally, most recent studies have failed to relate the ELP to the later appearing, larger pigment fraction that is derived from senescent erythrocytes.

These methodologic limitations have been circumvented by a new experimental approach using congenitally jaundiced Gunn rats (22). Since these animals are unable to conjugate bilirubin, they develop alternative catabolic pathways, which, at increased plasma bilirubin concentrations, result in a "steady state" between formation and breakdown of pigment (23). In individual rats 
the size and rate of turnover of the enlarged bilirubin pool can easily be measured (23), are nearly constant, and reflect a normal rate of hemoglobin catabolism (23). It is therefore possible to compute the rate of bile pigment production from labeled precursors on the basis of the sequential changes in specific activity of plasma bilirubin (24). Techniques were developed for crystallization of bilirubin and hemoglobin heme from very small blood samples, permitting accurate measurement of pigment production in intact animals over several months. In addition, corollary shortterm experiments were performed in normal rats with external bile drainage.

\section{Methods}

\section{Long-term studies in Gunn rats}

Rate of labeled bilirubin formation. Adult male homozygous Gunn rats weighing 253 to $475 \mathrm{~g}$ were used. Four to six weeks before the actual experiment the size and rate of turnover of the total miscible bilirubin pool were determined in each animal with bilirubin ${ }^{-14} \mathrm{C}$ (23). The isotopic precursors used for measurement of labeled bilirubin formation were 0.5 to $1.0 \mathrm{mc}$ glycine- $2{ }^{14} \mathrm{C}^{1}$ or $10 \mu \mathrm{c} \delta$-aminolevulinic acid (ALA) $-4-{ }^{14} \mathrm{C} .{ }^{2}$ The precursor, dissolved in isotonic saline, was injected intravenously in a single dose through a plastic catheter in a tail vein (25). To avoid anesthesia, we temporarily placed the rats in a restraining cage for injection. At the times indicated, 0.25 to $0.3 \mathrm{ml}$ blood was obtained from the tail; in animals with induced erythrocytosis, 0.4 to $0.55 \mathrm{ml}$ blood was removed to provide sufficient serum for analysis. Serum and clotted red cells were separated and stored at $-20^{\circ} \mathrm{C}$.

Bilirubin concentration was determined on $0.02 \mathrm{ml}$ serum by a micromodification of the Malloy and Evelyn method (26). For crystallization of labeled bilirubin, the technique of Weber and Schalm (27) was adapted as follows: $0.1 \mathrm{ml}$ serum and $0.15 \mathrm{ml}$ isotonic saline were added to the lactic acid-ethyl acetate-chloroform mixture. Unlabeled carrier bilirubin in chloroform was added to the separated chloroform phase, the combined solution was washed three to four times with water, once with $10 \mathrm{~g}$ per $100 \mathrm{ml} \mathrm{NaCl}$, again three to four times with water, and the bilirubin was then crystallized (28). Specific activity of twice recrystallized pigment was determined in a Packard Tri-Carb liquid scintillation spectrometer (28). The specific activity of bilirubin in the original serum sample was calculated by correcting for the amount of unlabeled carrier pigment added.

The change in specific activity of serum bilirubin was

${ }^{1}$ Glycine-2- ${ }^{14} \mathrm{C}$, 22 mc per mmole, New England $\mathrm{Nu}$ clear Corp., Boston, Mass.

${ }^{2}$ ALA $-4-{ }^{14} \mathrm{C}$ hydrochloride, $15.5 \mathrm{mc}$ per mmole, New England Nuclear Corp. used to compute the rate of labeled pigment formation during each interval between measurements (Figure 1). Calculations were done with a digital computer; the mathematical formulation is given in an appendix. The following assumptions were made: a) The rate of labeled pigment formation remains constant during each interval between measurements of specific activity, i.e., the process was regarded as a step function. This required frequent sampling of blood when rapid changes were anticipated. $b$ ) The labeled bilirubin mixes rapidly in the total miscible pigment pool.

In preliminary experiments, four Gunn rats were given glycine $-{ }^{14} \mathrm{C}$ or $\mathrm{ALA}-{ }^{14} \mathrm{C}$, and frequent blood samples were taken during the first 5 days. It was found that sampling at $1,3,13,28$, and 120 hours yielded a curve very similar to that obtained by more frequent analyses. Consequently, in the final studies, a total of only 11 to 13 blood samples was required from each rat to assess labeled pigment production over 82 days, when the experiments were terminated; in a few animals additional observations were made for another 2 to 3 weeks. In animals with normal erythropoiesis and total blood volumes of 19.8 to $22.3 \mathrm{ml}$ (29), this represented a cumulative blood loss in 82 days of 3.0 to $3.9 \mathrm{ml}$. In rats with induced erythrocytosis, blood volumes ranged from 21.3 to $27.7 \mathrm{ml}$, and a total of 3.9 to $5.6 \mathrm{ml}$ was removed for analysis. Hematocrit and reticulocyte count (30) were measured periodically.

Formation of labeled hemoglobin heme. Hemoglobin was recovered from the clotted red cells by repeated extraction with small volumes of $0.05 \mathrm{~N} \mathrm{NaOH}$. Volume and hemoglobin concentration (31) of the combined extracts were measured. A solution of unlabeled carrier hemoglobin was prepared by lysing saline-washed, packed rat erythrocytes in an equal volume of $0.05 \mathrm{~N} \mathrm{NaOH}$, followed by centrifugation at $31,500 \mathrm{~g}$ for 90 minutes. Carrier hemoglobin was added to the radioactive hemoglobin solution to yield a total of $200 \mathrm{mg}$, and the hemin

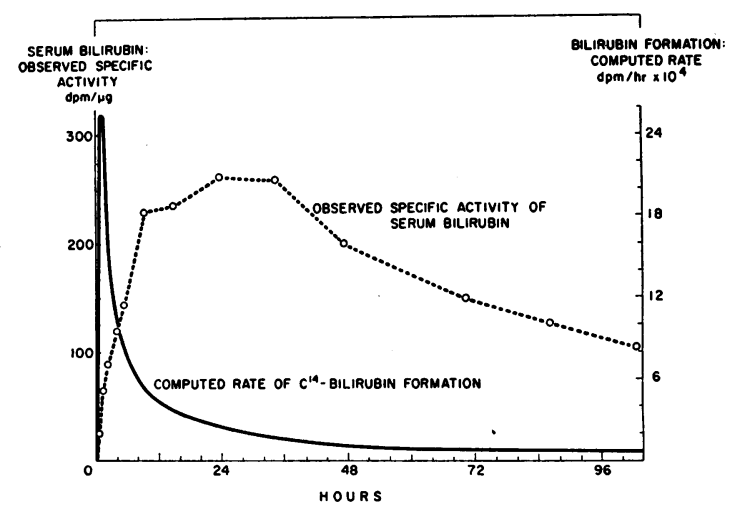

Fig. 1. Computation of early labeled pigment (ELP) FORMATION IN GUNN RAT GIVEN GLYCINE-2 $-{ }^{14} \mathrm{C}$ at TIME 0 . On the basis of the previously measured size and turnover rate of the miscible bilirubin pool, the rate of bilirubin- ${ }^{14} \mathrm{C}$ production was calculated from the consecutive changes in bilirubin specific activity. 
was then crystallized (32) and twice recrystallized (33). One mg hemin- ${ }^{14} \mathrm{C}$ was weighed on a Cahn electrobalance, combusted to ${ }^{14} \mathrm{CO}_{2}$ (34), and the specific activity determined in a Packard Tri-Carb liquid scintillation spectrometer. The specific activity of the original hemoglobin heme was calculated by correcting for the added carrier hemoglobin.

Validation of experimental procedures. Determination of the size and rate of turnover of the total miscible bilirubin pool was repeated in six Gunn rats 3 to $8 \frac{1}{2}$ months after the initial measurement. The mean difference between the two turnover rates was 5.6 ( $\mathrm{SD} \pm 5.1$ ) $\%$ of the mean value, and the mean difference between the two pool size measurements was 11.5 ( $\mathrm{SD} \pm 7.8$ ) \% of the mean value (35). In these six animals, the two values for pool size and for turnover rate were averaged for calculation of the rate of labeled pigment formation.

The technique for crystallization of bilirubin ${ }^{14} \mathrm{C}$ from small serum samples was checked by the following procedure: in six instances, radiochemically pure bilirubin${ }^{14} \mathrm{C}$ (28) of known specific activity was dissolved in a small volume of $0.05 \mathrm{~N} \mathrm{NaOH}$ in the dark, and this was immediately diluted with $10 \mathrm{vol}$ of rat serum. One-tenth $\mathrm{ml}$ of this solution was then used for crystallization and radioassay of bilirubin $-{ }^{14} \mathrm{C}$ by the microtechnique described. The resulting specific activity averaged 95.3 ( $\mathrm{SD} \pm 6.1) \%$ of the starting material.

On several occasions bilirubin $-{ }^{14} \mathrm{C}$ was obtained by the microprocedure from rats soon after injection with glycine ${ }^{14} \mathrm{C}$ and recrystallized three times. Determination of specific activity after each crystallization showed no significant changes.

The procedure for crystallization and radioassay of hemoglobin heme from small blood samples was checked in six instances by comparing the specific activity so determined with that obtained by direct crystallization of hemin $(32,33)$ from larger volumes of the same blood. The specific activity measured by the microprocedure averaged $96.3(\mathrm{SD} \pm 5.4) \%$ of that found by direct crystallization.

As an additional control experiment, hemin was crystallized by the microprocedure from the tail blood of a rat given $100 \mu \mathrm{c}$ glycine- ${ }^{14} \mathrm{C} 30$ minutes earlier. Immediately thereafter, $10 \mathrm{ml}$ heparinized blood was collected by cardiac puncture, the red cells were washed three times with cold isotonic saline, and the hemin was crystallized. The specific activity of hemin prepared by the microprocedure was virtually identical to that found by direct crystallization of cardiac blood.

The reproducibility of the combustion procedure for measuring radioactivity of hemin $-{ }^{14} \mathrm{C}$ was demonstrated in the following way: a few micrograms of hemin $-{ }^{14} \mathrm{C}$ of high specific activity was dissolved directly in hydroxide of Hyamine $\mathbf{s}$ and counted in a Packard Tri-Carb liquid scintillation spectrometer, and 1-mg portions of the same hemin $-{ }^{14} \mathrm{C}$ samples were combusted to ${ }^{14} \mathrm{CO}_{2}$ for counting. The radioactivity recovered by combustion ranged from 95 to $102 \%$ of that measured by direct radioassay.

\footnotetext{
3 Packard Instrument Co., La Grange, Ill.
}

Short-term studies in normal rats with external bile drainage

Unless otherwise specified, male rats of the inbred Fischer 344 strain 4 weighing from 280 to $397 \mathrm{~g}$ were used. Under ether anesthesia, a PE-50 polyethylene catheter ${ }^{5}$ was inserted into the common bile duct, and the animal was placed in a modified Bollman restraining cage for continuous collection of bile. A tapered PE-60 polyethylene catheter ${ }^{5}$ was inserted into a tail vein (25) for intravenous injection of the labeled precursors and for continuous infusion of isotonic saline at a rate of $1 \mathrm{ml}$ per hour. The animals had free access to laboratory chow and drinking water.

Three to 5 hours after surgery, $100 \mu \mathrm{c}$ glycine $-2-{ }^{14} \mathrm{C}$ or $10 \mu \mathrm{c}$ ALA $-4-{ }^{14} \mathrm{C}$ was injected in a single dose. Bile was collected in the dark in graduated tubes immersed in ice. Tubes were changed at $\frac{3}{4}, 1 \frac{1}{2}, 2 \frac{1}{2}, 4 \frac{1}{2}$, and 9 hours and less frequently thereafter. Volume and bilirubin concentration (26) of each bile sample were measured, and the bilirubin was crystallized (28). Small bile samples were diluted with rat bile containing known amounts of unlabeled carrier bilirubin. The specific activity of the bilirubin- ${ }^{14} \mathrm{C}$ was determined on twice recrystallized pigment (28). Approximately once each day, blood samples were obtained from the tail for radioassay of hemin, as previously described. Experiments were carried out for periods of 3 to 8 days.

The effect of surgery and anesthesia on the rate of labeled heme and bile pigment formation was evaluated in the following way. In a few animals with external bile drainage, administration of isotopic precursor was delayed until 20 hours, instead of the usual 3 to 5 hours, after surgery. In both groups of animals, similar results were obtained. In addition, isotope incorporation into hemoglobin heme was determined in two intact rats given $100 \mu \mathrm{c}$ glycine $-{ }^{14} \mathrm{C}$.

\section{Stimulation and suppression of erythropoiesis}

Long-term studies in Gunn rats. A male Gunn rat with initial weight of $307 \mathrm{~g}$ and hematocrit of $45 \%$ was given daily subcutaneous injections of erythropoietin ${ }^{\circ}$ for 200 consecutive days (36). The dose was $7 \mathrm{U}$ per $100 \mathrm{~g}$ body weight per day. The hematocrit progressively increased to a maximum of 72 to $74 \%$ at about 6 weeks. Two weeks after stabilization of hematocrit, size and rate of turnover of the miscible bilirubin pool were measured with bilirubin- ${ }^{14} \mathrm{C}$ (23). Seven weeks later, $0.5 \mathrm{mc}$ glycine- ${ }^{14} \mathrm{C}$ was administered, and labeled heme and bile pigment formation were measured over the ensuing 91 days. Throughout the experiment the hematocrit remained between 70 and $74 \%$, and the animal gained a moderate amount of weight.

Three Gunn rats were exposed to hypoxia for several months in a low pressure chamber ${ }^{7}$ maintained at a
4 A. R. Schmidt Co., Madison, Wisc.
5 Clay-Adams, Inc., New York, N. Y.
- Obtained from the Erythropoietin Committee of the National Heart Institute.
${ }^{7}$ Kindly made available by Dr. Clifford Gurney. 
pressure of 0.5 atmosphere. Hematocrits stabilized at 75 to $82 \%$, and after about 6 weeks the size and turnover rate of the bilirubin pool were measured. Four weeks later, the rats were given glycine ${ }^{14} \mathrm{C}$. Studies could not be completed in any of these animals. One rat died within a few days, and although the other two appeared well and gained weight initially, they died 5 and 8 weeks after isotope administration.

Short-term studies in Fischer rats with external bile drainage. Three Fischer rats were placed in a low pressure chamber at 0.5 atmosphere for 7 days. The animals were then removed from the chamber for 5 hours for bile duct cannulation and injection of radioactive precursor. During the remainder of the experiment the rats were exposed continuously to the reduced atmospheric pressure, except for short periods when bile collection tubes were changed and blood samples taken.

In three rats, 5 to $6 \mathrm{ml}$ blood was removed by cardiac puncture on the eleventh, sixth, and third days before cannulation of the bile duct and subsequent administration of isotope.

In three rats, erythropoiesis was suppressed by intravenous transfusion of packed isologous red cells 15, 10, and 7 days before insertion of the bile duct cannula. Each transfusion represented about $12 \mathrm{ml}$ whole blood, the equivalent of $70 \%$ of the recipient's original blood volume. The adequacy of erythroid suppression was ascertained by similarly hypertransfusing three additional rats not subjected to bile duct cannulation but instead sacrificed for morphologic analysis of femoral and vertebral bone marrow. Bone marrow morphology was also studied in three control rats of comparable weight.

In each of the three experimental groups with stimulated or suppressed erythropoiesis, two animals received 100 $\mu \mathrm{c}$ glycine- $2-{ }^{14} \mathrm{C}$ and one received $10 \mu \mathrm{c}$ ALA-4- ${ }^{14} \mathrm{C}$.

\section{Miscellaneous studies}

Experiments with hemin $-{ }^{14} \mathrm{C}$ as precursor. Hemin- ${ }^{14} \mathrm{C}$ of 440 to $650 \mathrm{dpm}$ per $\mu \mathrm{g}$ SA was crystallized $(32,33)$ from blood of rats injected with 1 to $2 \mathrm{mc}$ glycine- $2-{ }^{14} \mathrm{C}$. ${ }^{50} \mathrm{Fe}$-labeled hemin containing $600 \mathrm{dpm}$ per $\mu \mathrm{g}$ was obtained from a rat injected 9 days earlier with $40 \mu \mathrm{c}$ citrate ${ }^{58} \mathrm{Fe}^{8}$ Weighed portions of labeled hemin for injection were dissolved in $0.1 \mathrm{ml} 0.05 \mathrm{~N} \mathrm{NaOH}$ and added to 1.0 to $2.5 \mathrm{ml}$ rat serum.

Two Fischer rats with external bile fistulas were given intravenous injections of 66 and $126 \mu \mathrm{g}$ hemin $-{ }^{14} \mathrm{C}$, respectively, and biliary excretion of bilirubin $-{ }^{14} \mathrm{C}$ was determined. The removal rate of hemin $-{ }^{14} \mathrm{C}$ from the plasma was estimated from the radioactivity in serum samples taken at frequent intervals.

Similar experiments were carried out in three intact Gunn rats. The animals were injected with the following doses of hemin: $123 \mu \mathrm{g}$ hemin ${ }^{14} \mathrm{C}$; $128 \mu \mathrm{g}$ hemin $-{ }^{14} \mathrm{C}$ mixed with $123 \mu \mathrm{g}$ hemin $-{ }^{50} \mathrm{Fe}$; and $261 \mu \mathrm{g}$ hemin $-{ }^{14} \mathrm{C}$ mixed with $249 \mu \mathrm{g}$ hemin $-{ }^{59} \mathrm{Fe}$. The rate of bilirubin $-{ }^{14} \mathrm{C}$ formation during the next 28 to 30 hours was computed from the specific activity of bilirubin $-{ }^{14} \mathrm{C}$ in the plasma.

\footnotetext{
8 Abbott Laboratories, North Chicago, Ill.
}

The rate of hemin removal from the plasma was measured by using the ${ }^{50} \mathrm{Fe}$ label, assuming a negligible contribution from recirculating transferrin-bound ${ }^{50} \mathrm{Fe}$.

Effect of drugs on bilirubin formation. At 20 days of age, a group of Fischer rats was placed on a diet of pulverized Purina laboratory chow containing $2.5 \%$ (wt/wt) powdered griseofulvin. Control animals received the same diet without the drug. After 58 days on this diet, when the animals had reached 240 to $300 \mathrm{~g}$, bile duct cannulas were inserted. In both the drug and control groups, two rats were given ALA $-{ }^{14} \mathrm{C}$ and one glycine- ${ }^{14} \mathrm{C}$. Just before surgery, stool was analyzed for porphyrin concentration (37), but no detectable increase was noted in the griseofulvin-treated rats.

A 237-g male Sprague-Dawley rat with an external bile fistula was infused intravenously with allylisopropylacetamide $^{9}$ (AIA) at a rate of $7 \mathrm{mg}$ per hour for 42 hours. The urine showed a positive porphobilinogen reaction (38). The animal was then injected with $100 \mu \mathrm{c}$ glycine-2- ${ }^{14} \mathrm{C}$, and bile samples were collected over the ensuing 24 hours. The AIA infusion was continued for the duration of the experiment. Five other SpragueDawley rats served as controls.

\section{Presentation of results}

Formation of bilirubin- ${ }^{14} \mathrm{C}$. In Gunn rats, formation of labeled bile pigment is expressed in terms of the consecutive rates at which bilirubin $-{ }^{14} \mathrm{C}$ entered the bilirubin pool of the animals, i.e., as disintegrations per minute per hour in bilirubin $-{ }^{14} \mathrm{C}$ that gained access to the pool. As noted, computation was facilitated by assuming that the rate of labeled pigment formation remains constant during each interval between determinations of bilirubin $-{ }^{14} \mathrm{C}$ specific activity. For presentation of the data, the rate of labeled bilirubin formation was plotted at the median time of each interval so that smooth curves could be drawn.

Similarly, in the short-term studies in rats with external bile drainage, formation of labeled pigment is expressed in disintegrations per minute per hour in bilirubin- ${ }^{14} \mathrm{C}$ excreted in the bile. For direct comparison of results in animals subjected to different procedures and injected with different labeled precursors, all curves were adjusted to a standard isotope dose of $1.0 \mathrm{mc}$ glycine $-{ }^{14} \mathrm{C}$, ALA $-{ }^{14} \mathrm{C}$, or hemin $-{ }^{14} \mathrm{C}$.

Fractional incorporation of the isotopic precursor into bilirubin $-{ }^{14} \mathrm{C}$ was calculated and recorded for arbitrary time intervals selected on the basis of the findings in rats with physiologic erythropoiesis: early phase of ELP, 0 to $3 \frac{1}{2}$ hours after isotope administration; late phase of ELP, $3 \frac{1}{2}$ to 60 hours; plateau of labeled pigment formation, $2 \frac{1}{2}$ to 42 days; and late peak of labeled pigment formation, 42 to 82 days. Incorporation during the last two intervals could be calculated only for Gunn rats. In these animals, the bilirubin- ${ }^{14} \mathrm{C}$ formed during each interval was also expressed as per cent of the total pigment produced over the entire 82 days.

\footnotetext{
${ }^{9}$ Kindly supplied by Dr. Alfred Pletscher, HoffmannLaRoche, Inc., Basel, Switzerland.
} 
Production of hemoglobin heme- ${ }^{14} C$. Total radioactivity (disintegrations per minute) in circulating hemoglobin heme at the time of sampling was calculated from the specific activity of the isolated hemin. The hemin equivalent of the circulating red cell mass was computed from the hemoglobin concentration and an estimated blood volume of 4.5 to $6.0 \%$ of body weight, based on the size of the animal (29). Per cent incorporation of the labeled precursor into total hemoglobin heme $-{ }^{14} \mathrm{C}$ was also calculated.

When the hematologic status of animals was altered, the following adjustments were made in calculating blood vQlume: $a$ ) In hypertransfused rats we assumed that endogenous red cell formation ceased after the first transfusion and that the transfused cells had an average life span of 60 days; a minor allowance was made for traumatic loss of blood during transfusion. The computed blood volumes in the three rats were $11.6,11.8$, and $12.1 \%$ of body weight, compared to $5.5 \%$ in control animals of the same size (29). b) Rats chronically exposed to 0.5 atmosphere pressure have an average increase in blood volume of $43 \%$ (39). Thus, we assumed a blood volume of $8.6 \%$ for the three Gunn rats maintained in the low pressure chamber. We estimated a corresponding figure of $7.9 \%$ for the Gunn rat treated with erythropoietin. Hematologically normal rats of comparable size have blood volumes of 6.0 and $5.5 \%$, respectively (29). c) In rats exposed to 0.5 atmosphere pressure for only 1 week, we assumed that the rise in blood volume was proportional to the increase in hematocrit, taking as end points the blood volume(39) and hematocrit of animals subjected to hypoxia for several months. This resulted in an estimated blood volume of $7.4 \%$, compared to $6.0 \%$ in normal rats of similar weight. $d$ ) In rats with anemia, we assumed that the blood volume fell $5 \%$ for each $10 \%$ reduction in hemoglobin concentration $(40,41)$.

\section{Results}

\section{Rats with normal erythropoiesis}

Glycine-2-14C as precursor. Formation of hemoglobin heme- $-{ }^{14} \mathrm{C}$ and bilirubin- ${ }^{14} \mathrm{C}$ was studied in four Gunn rats with normal erythropoiesis for 82 days after glycine- ${ }^{14} \mathrm{C}$ administration. In two additional animals, measurements were made only during the initial 5 days. Results of a representative experiment are shown in Figure 2.

Isotope was detectable in circulating hemoglobin heme within $\frac{1}{2}$ hour of glycine- ${ }^{14} \mathrm{C}$ administration, and it reached its highest concentration in 3 to 5 days (Figure 2, Table I). Activity of ${ }^{14} \mathrm{C}$ in heme of circulating red cells declined gradually over the ensuing 5 to 6 weeks, but it then fell off more rapidly between days 42 and 82 . Thereafter, radioactivity decreased more slowly and approached but did not reach base line even when

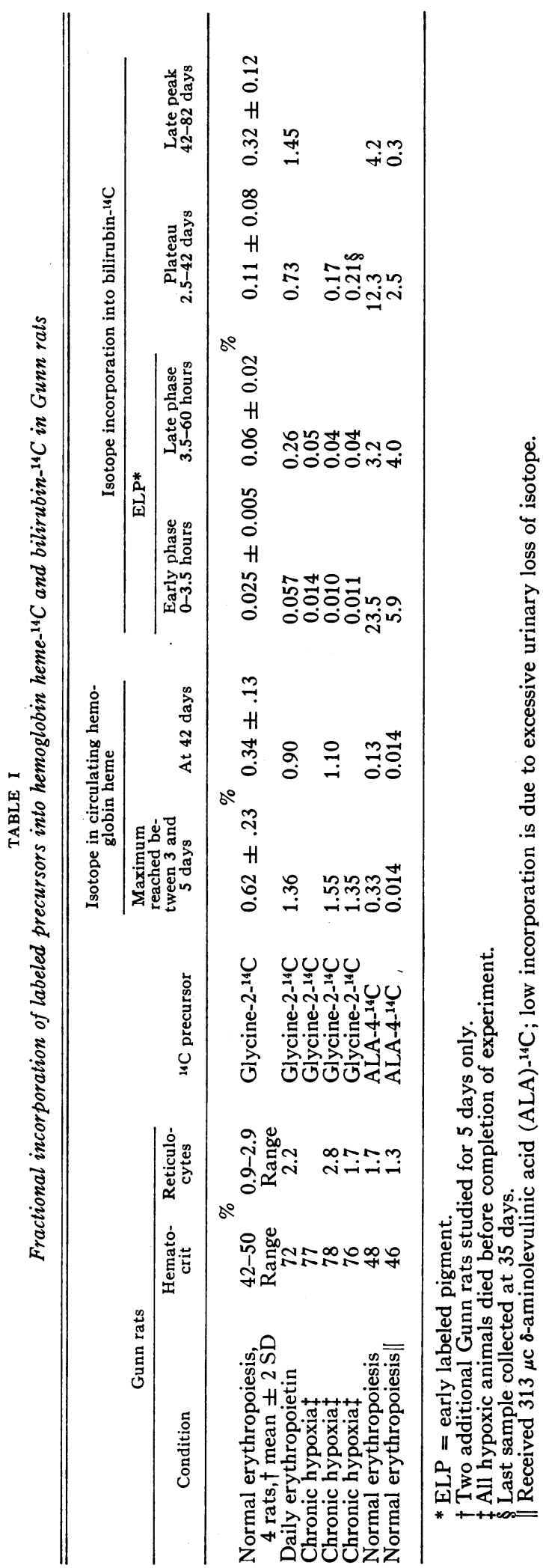



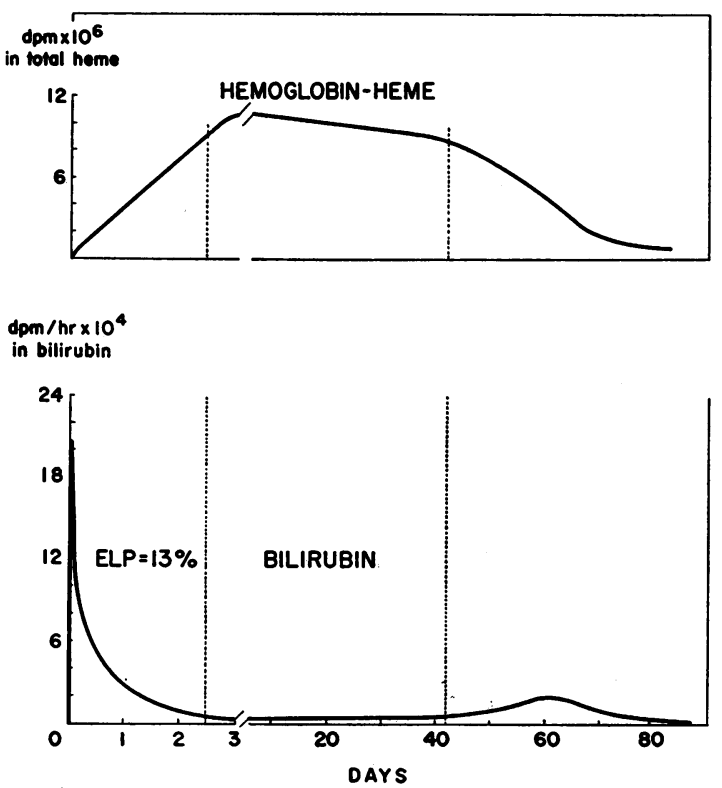

Fig. 2. Formation of HeMoglobin HeMe- ${ }^{14} \mathrm{C}$ AND BILIRUbin- ${ }^{14} \mathrm{C}$ in GUNN RAT Given GLYCINE-2 $-{ }^{14} \mathrm{C}$.

observations were made up to 100 days. The persistence of low-grade labeling in hemoglobin heme is probably due to reutilization of isotope entering the glycine pool from turnover of labeled proteins, including globin (42).

The late peak of labeled bile pigment formation occurred between 42 and 82 days, coinciding with the rapid decline of ${ }^{14} \mathrm{C}$ activity in hemoglobin heme (Figure 2). During this interval, $0.32 \%$ of the administered isotope appeared in bilirubin- ${ }^{14} \mathrm{C}$ (Table I). Because one labeled carbon atom is lost on cleavage of the porphyrin ring (28), this corresponds to $0.37 \%$ of isotope in heme. By comparison, shortly before the beginning of ac- celerated erythrocyte removal at 42 days, $0.34 \%$ of the injected glycine- ${ }^{14} \mathrm{C}$ was present in circulating hemoglobin heme (Table I). These findings indictate that rat erythrocytes have an average lifespan of about 60 days and that hemoglobin in senescent erythrocytes accounts for virtually all bilirubin $-{ }^{14} \mathrm{C}$ produced during the late peak. The latter, on the average, comprised $62.5 \%$ of all labeled bile pigment formed during the entire 82 days (Table II).

In addition, random loss of some labeled red cells was suggested by the gradual decline of isotope in circulating hemoglobin heme between 3 to 5 and 42 days (Figure 2, Table I). Most of the bilirubin $-{ }^{14} \mathrm{C}$ produced during this plateau interval appeared to be derived from these randomly destroyed erythrocytes and amounted to an average of $21.5 \%$ of the total labeled bile pigment (Table II).

The remaining $16 \%$ of the labeled bilirubin was produced during the initial $2 \frac{1}{2}$ days, comprising the early labeled pigment. The rate of ELP formation (Figure 3) was maximal between 1 and 2 hours, rapidly decreased during the next 2 hours, and thereafter declined more slowly to approach base-line levels between 2 and 3 days. This is in contrast to studies in man and dogs $(16-18)$, in which a major fraction of the ELP was observed between 3 and 5 days. The configuration of the curves suggested that the ELP includes two components, an early phase during the initial $3 \frac{1}{2}$ hours, and a late phase extending from $3 \frac{1}{2}$ to approximately 60 hours. During the brief early phase the rate of bilirubin- ${ }^{14} \mathrm{C}$ formation was very high and accounted for approximately one-fourth of the entire ELP (Table II). On the other hand, ${ }^{14} \mathrm{C}$ activity

TABLE II

Proportion of total bilirubin- ${ }^{14} \mathrm{C}$ formed by Gunn rats during different intervals after isotope administration

\begin{tabular}{|c|c|c|c|c|c|}
\hline \multirow[b]{3}{*}{ Gunn rats } & \multirow[b]{3}{*}{${ }^{14} \mathrm{C}$ precursor } & \multicolumn{4}{|c|}{ Bilirubin-14C formed } \\
\hline & & \multicolumn{2}{|c|}{ ELP } & \multirow[b]{2}{*}{$\begin{array}{l}\text { Plateau } \\
\text { 2.5-42 days }\end{array}$} & \multirow[b]{2}{*}{$\begin{array}{l}\text { Late peak } \\
42-82 \text { days }\end{array}$} \\
\hline & & $\begin{array}{l}\text { Early phase } \\
0-3.5 \text { hours }\end{array}$ & $\begin{array}{l}\text { Late phase } \\
3.5-60 \text { hours }\end{array}$ & & \\
\hline & & \multicolumn{4}{|c|}{$\%$ of total* } \\
\hline $\begin{array}{l}\text { Normal, } 4 \text { rats, } \\
\text { mean } \pm 2 \text { SD }\end{array}$ & Glycine- $2-{ }^{14} \mathrm{C}$ & $5.0 \pm 1.8$ & $11.0 \pm 2.8$ & $21.5 \pm 11.2$ & $62.5 \pm 10.6$ \\
\hline $\begin{array}{l}\text { Daily erythropoietin } \\
\text { Normal } \\
\text { Normal } \dagger\end{array}$ & $\begin{array}{l}\text { Glycine-2-14 C } \\
\text { ALA-4- }{ }^{14} \mathrm{C} \\
\text { ALA }-4-{ }^{14} \mathrm{C}\end{array}$ & $\begin{array}{r}2.3 \\
54.5 \\
46.2\end{array}$ & $\begin{array}{r}10.5 \\
7.3 \\
31.5\end{array}$ & $\begin{array}{l}29.1 \\
28.5 \\
19.6\end{array}$ & $\begin{array}{r}58.1 \\
9.7 \\
2.7\end{array}$ \\
\hline
\end{tabular}

* Total is defined as all bilirubin- ${ }^{14} \mathrm{C}$ formed between 0 and 82 days.

$\dagger$ Received large dose of ALA- ${ }^{14} \mathrm{C}$. 

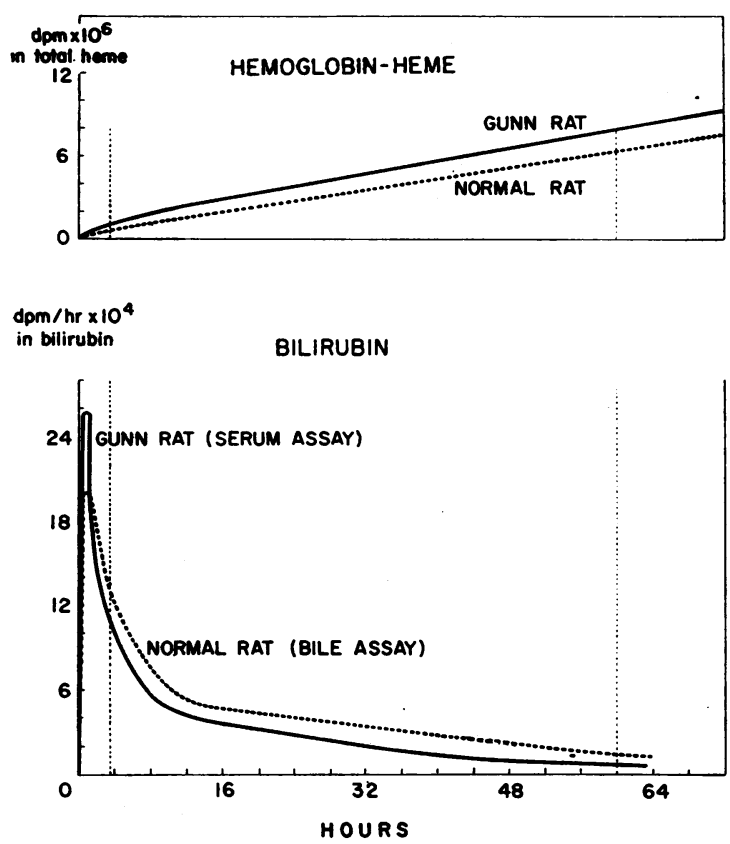

Fig. 3. Formation of HEMOgLOBIN HEME- ${ }^{14} \mathrm{C}$ AND ELP FROM GLYCINE-2- ${ }^{14} \mathrm{C}$. Comparison of results in a Gunn rat and in a Fischer rat with external bile drainage.

in circulating hemoglobin heme was very low during the early phase of ELP but gradually rose during the subsequent $2 \frac{1}{2}$ days, concomitant with a progressive fall in the rate of bilirubin- ${ }^{14} \mathrm{C}$ formation (Figure 3 ).

$A L A-4-{ }^{14} C$ as precursor. Two Gunn rats with normal erythropoiesis were given ALA $-4-{ }^{14} \mathrm{C}$ and studied for 82 days. The results in these two animals are not strictly comparable, because an excessive amount of $\mathrm{ALA}-{ }^{14} \mathrm{C}$ was given to one animal in an early experiment, resulting in significant urinary excretion of isotope (43) and therefore in reduced fractional incorporation of ALA into heme and bile pigment (Table I).

Fractional isotope incorporation into erythrocyte heme was smaller with ALA than with glycine (Table I). Although maximal labeling of hemoglobin heme in one animal (Figure 4) occurred between 1 and 2 days, in the other rats given ALA $-{ }^{14} \mathrm{C}$ highest values usually were reached around 3 days (Figure 5 ).

In contrast to the findings for hemoglobin heme, the fractional incorporation of $\mathrm{ALA}-{ }^{14} \mathrm{C}$ into bilirubin was much greater than it was with glycine (Table I), and most of this labeled pigment was produced during the initial few hours (Table II).
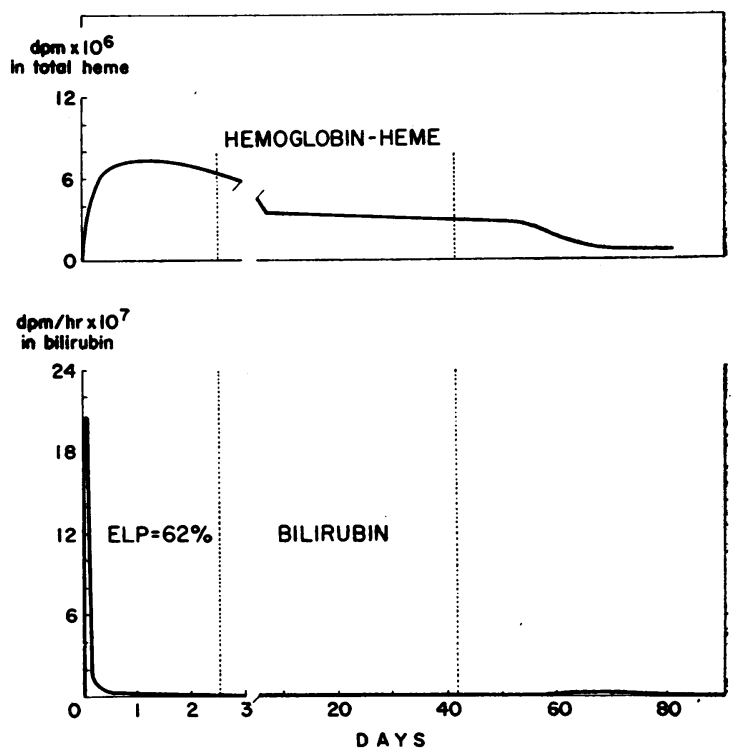

Fig. 4. Formation of heMroglobin Heme- $-{ }^{14} \mathrm{C}$ and BILIRUBIN- ${ }^{14} \mathrm{C}$ IN GUNN RAT GIVEN $\delta$-AMINOLEVULINIC ACID (ALA) $-4-{ }^{14} \mathrm{C}$.

The maximal rate of labeled pigment formation from $\mathrm{ALA}-{ }^{14} \mathrm{C}$ was $20 \times 10^{7} \mathrm{dpm}$ per hour (Figure 4), compared to only $20 \times 10^{4} \mathrm{dpm}$ per hour with glycine- ${ }^{14} \mathrm{C}$ (Figure 2 ). The kinetics of ELP formation from $\mathrm{ALA}-{ }^{14} \mathrm{C}$ (Figure 5) resembled those of the early phase of the curve obtained with glycine- ${ }^{14} \mathrm{C}$ (Figure 3 ). Bilirubin- ${ }^{14} \mathrm{C}$ production
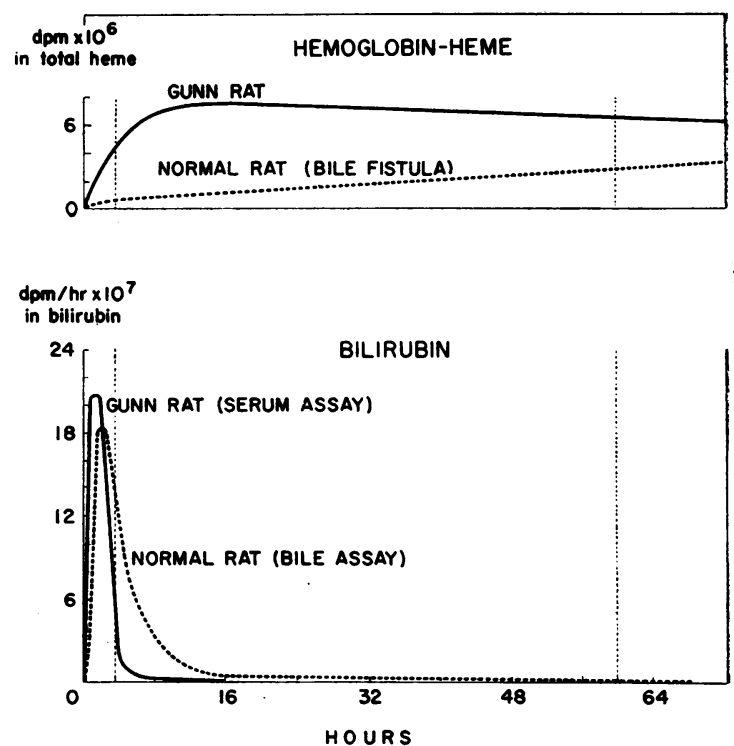

Fig. 5. Formation OF HEMOgLOBIN HEME- ${ }^{14} \mathrm{C}$ AND ELP FROM ALA $-4-{ }^{14} \mathrm{C}$. Comparison of results in a Gunn rat and in a Fischer rat with external bile drainage. 
from ALA was maximal at 1 to 2 hours, as it was with glycine, but it then fell off much more rapidly and approached base-line levels between 4 and 8 hours.

The disproportionately large incorporation of ALA- ${ }^{14} \mathrm{C}$ into bilirubin as compared with hemoglobin heme indicated that bile pigment formed from $\mathrm{ALA}-{ }^{14} \mathrm{C}$ arose largely from nonhemoglobin sources. This was reflected by the fact that destruction of senescent red cells after 42 days gave rise to comparatively little bilirubin $-{ }^{14} \mathrm{C}$ (Figure 4 ), the late peak representing only 3 to $10 \%$ of the total bile pigment formed during the entire 82 days (Table II). On the other hand, the ELP accounted for 62 to $78 \%$ of the total bilirubin $-{ }^{14} \mathrm{C}$ produced.

The dissociation between formation of bile pigment and turnover of hemoglobin was not confined to ELP, but was noticeable in the later stages of bile pigment formation. During the plateau from $2 \frac{1}{2}$ to 42 days and the late peak from 42 to 82 days, fractional ALA $-{ }^{14} \mathrm{C}$ incorporation into bilirubin${ }^{14} \mathrm{C}$ was 20 to 60 times larger than the total amount of radioactivity present in circulating hemoglobin heme (Table I). For example, in Figure 4, if all heme- ${ }^{14} \mathrm{C}$ present in red cells at 42 days had been converted to bilirubin $-{ }^{14} \mathrm{C}$ at a constant rate during the subsequent 40 days (late peak), labeled bile pigment would have been formed at the rate of 28 dpm per hour. Instead, the actual values observed were $80,220,280,1,260,2,710$, and $280 \mathrm{dpm}$ per hour.

These observations indicate that less than $1 \%$ of the total labeled bilirubin formed from ALA $-{ }^{14} \mathrm{C}$ was derived from labeled heme in circulating red cells. By contrast, with glycine $-{ }^{14} \mathrm{C}$ as precursor, more than $80 \%$ of the total labeled bilirubin originated from red cell hemoglobin, this source accounting for virtually all pigment formed during the late peak and most of that produced during the plateau interval.

Short-term studies in rats with external bile drainage. Four animals with normal erythropoiesis were given glycine-2- ${ }^{14} \mathrm{C}$, and five were given ALA-4- ${ }^{14} \mathrm{C}$ (Table III). The findings were similar to those obtained in the Gunn rats (Tables I and III, Figures 3 and 5), confirming the validity of the mathematical assumptions made for the longterm studies. The maximal rate of bilirubin $-{ }^{14} \mathrm{C}$ formation usually occurred between 1 and 2 hours, and the total ${ }^{14} \mathrm{C}$ incorporation into ELP did not differ significantly in the two groups of animals. However, in rats with a bile fistula, the apogee of the ELP curves frequently was slightly lower and was reached a little later than in the Gunn rats (Figures 3 and 5), and the curves approached base line more gradually. These minor differences probably were due in part to a short delay in mixing of newly formed bilirubin ${ }^{14} \mathrm{C}$. in the pigment pool of the Gunn rats. Biological variation be-

TABLE III

Fractional incorporation of labeled precursors into hemoglobin heme- ${ }^{14} \mathrm{C}$ and bilirubin ${ }^{14} \mathrm{C}$ in rats with external bile drainage

\begin{tabular}{|c|c|c|c|c|c|c|}
\hline \multirow{3}{*}{ Rats } & \multirow{3}{*}{ Hematocrit } & \multirow{3}{*}{ Reticulocytes } & \multirow{3}{*}{${ }^{14} \mathrm{C}$ precursor } & \multirow{3}{*}{$\begin{array}{c}\text { Maximal isotope } \\
\text { in circulating } \\
\text { hemoglobin heme } \\
\text { between } 3 \text { and } \\
5 \text { days }\end{array}$} & \multirow{2}{*}{\multicolumn{2}{|c|}{$\begin{array}{c}\begin{array}{c}\text { Isotope incorporation into } \\
\text { bilirubin-14C }\end{array} \\
\text { ELP }\end{array}$}} \\
\hline & & & & & & \\
\hline & & & & & $\begin{array}{l}\text { Early phase } \\
0-3.5 \text { hours }\end{array}$ & $\begin{array}{l}\text { Late phase } \\
3.5-60 \text { hours }\end{array}$ \\
\hline & \multicolumn{2}{|c|}{$\%$} & & $\%$ & \multicolumn{2}{|c|}{$\%$} \\
\hline Normal erythropoiesis, & $44-49$ & $1.5-2.4$ & Glycine-2-14C & $0.37 \pm 0.16$ & $0.020 \pm 0.006$ & $0.09 \pm 0.02$ \\
\hline 4 rats, mean $\pm 2 \mathrm{SD}$ & Range & Range & & & & \\
\hline Hemorrhage & $30^{\circ}$ & 12.7 & Glycine-2-14C & $0.41^{*}$ & 0.015 & 0.15 \\
\hline Hemorrhage & 38 & 27.1 & Glycine-2-14C & $0.91^{*}$ & 0.023 & 0.15 \\
\hline Acute hypoxia & 60 & 10.0 & Glycine-2-14C & 1.76 & 0.020 & 0.19 \\
\hline Acute hypoxia & 61 & 7.7 & Glycine-2-14 C & 1.44 & 0.024 & 0.21 \\
\hline Hypertransfusion & 70 & 0.3 & Glycine-2-14C & 0.017 & 0.022 & 0.10 \\
\hline Hypertransfusion & 71 & 0.1 & Glycine-2-14C & 0.011 & 0.021 & 0.07 \\
\hline Normal erythropoiesis, & $44-49$ & $1.5-2.4$ & ALA-4- ${ }^{14} \mathrm{C}$ & $0.18 \dagger$ & $15.9 \pm 4.7$ & $19.6 \pm 9.4$ \\
\hline 5 rats, mean $\pm 2 S D$ & Range & Range & & & & \\
\hline Hemorrhage & $34^{\circ}$ & 11.7 & ALA-4-14C & 0.18 & 9.8 & 31.4 \\
\hline Acute hypoxia & 63 & 10.3 & ALA-4- ${ }^{14} \mathrm{C}$ & 0.29 & 24.1 & 28.6 \\
\hline Hypertransfusion & 67 & 0.1 & ALA-4- ${ }^{14} \mathrm{C}$ & 0.029 & 30.6 & 17.1 \\
\hline
\end{tabular}

${ }^{*}$ Last sample measured at 51 hours; ${ }^{14} \mathrm{C}$ activity in circulating hemoglobin heme may be underestimated. $\dagger$ Average value from two rats. 
tween the inbred Fischer and the Gunn rat (mutant Wistar strain) may have played an additional role. Because of these small differences in the two groups of animals, arbitrary division of the ELP at $3 \frac{1}{2}$ hours did not yield strictly comparable numerical relationships between early and late phases of ELP (Tables I and III), but this can readily be adjusted on visual inspection of the respective curves (Figures 3 and 5 ).

Maximal isotope incorporation into circulating hemoglobin heme was higher in Gunn rats than in animals with external bile drainage (Tables $I$ and III, Figures 3 and 5). This can be attributed to transient depression of hemopoietic activity after anesthesia and surgery. In the Gunn rats $0.62 \%$ of the administered glycine- ${ }^{14} \mathrm{C}$ was incorporated into hemoglobin heme; in two intact Fischer rats, the comparable value was $0.72 \%$, whereas incorporation was $0.37 \%$ in the four animals subjected to surgery.

Bilirubin- ${ }^{14} C$ formation from hemin $-{ }^{14} C$. The average half-time for disappearance of hemin from the plasma was 2.7 hours in the Gunn rats and 2.6 hours in the Fischer rats with external bile drainage (Figure 6 ). Total recovery of isotope in bilirubin- ${ }^{14} \mathrm{C}$ during the first 24 hours was $40.1 \%$ in the Gunn rats and $65.1 \%$ in the animals with bile fistulas. These findings are similar to data previously reported (44). The maximal rate of bilirubin- ${ }^{14} \mathrm{C}$ formation was reached 2 to 4 hours after injection of the hemin- ${ }^{14} \mathrm{C}$ (Figure 6). In the two groups of animals, the configuration of the curves for labeled bile pigment production exhibited small differences similar to those observed for ELP formation from glycine- ${ }^{14} \mathrm{C}$ and $\mathrm{ALA}-{ }^{14} \mathrm{C}$ (Figures 3 and 5).

\section{Stimulation and suppression of erythropoiesis}

Glycine-2-14C as precursor. In Figure 7, the findings in the Gunn rat with chronic erythroid hyperplasia maintained by daily injection of erythropoietin are compared with those in four animals with normal erythropoiesis. There was enhanced fractional incorporation of glycine- ${ }^{14} \mathrm{C}$ into both circulating hemoglobin heme and bile pigment (Table I). ELP formation was increased, but most of the increase occurred during the late phase, in which $0.26 \%$ of the isotope appeared in bilirubin- $-{ }^{14} \mathrm{C}$, as compared to only $0.06 \%$ in the controls. The initial ELP component also seemed to

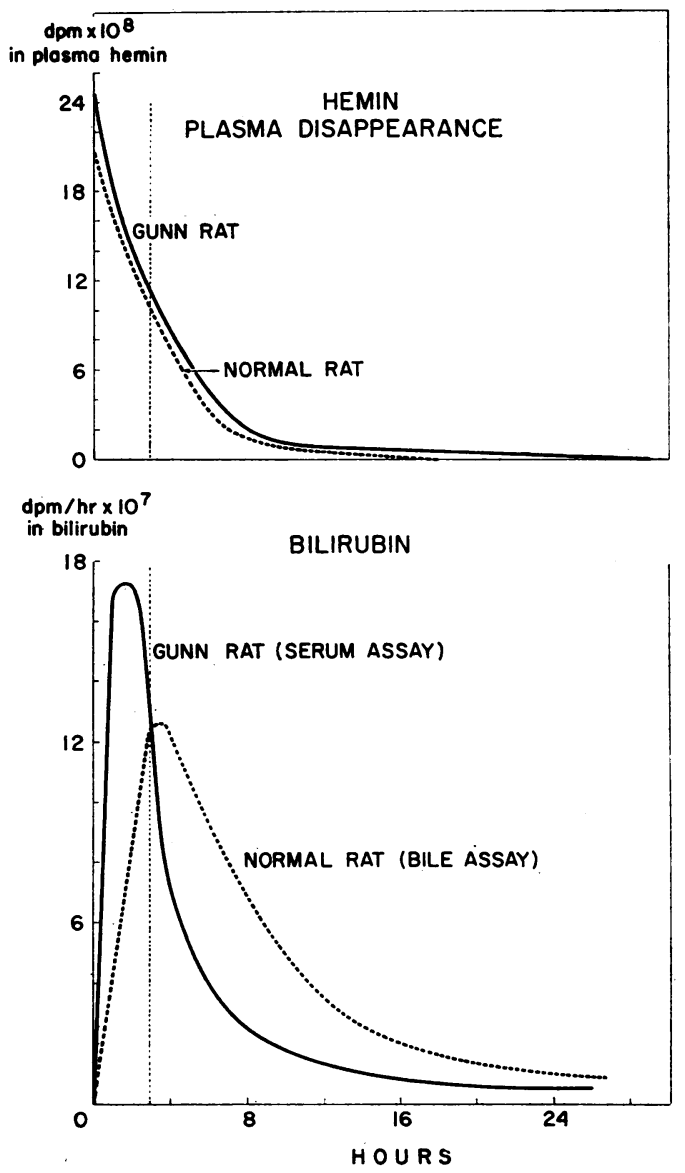

Fig. 6. Formation of BILIRUBIN- $-{ }^{14} \mathrm{C}$ From hemin $-{ }^{14} \mathrm{C}$ in a GunN RAt and in a Fischer rat with eXternal BILE DRAINAGE.

be enlarged, but to a lesser extent (Table I, Figure 7). This was the only instance in which erythroid stimulation led to an apparent augmentation of bilirubin ${ }^{-14} \mathrm{C}$ production between 0 and 3.5 hours (Tables I and III).

The increase in ELP production was associated with a commensurate rise in bilirubin $-{ }^{14} \mathrm{C}$ formation during the plateau interval ( $2 \frac{1}{2}$ to 42 days) and the late peak, so that the pattern of labeled pigment production over the entire 82 days remained proportionate to that of control animals (Table II). Thus, the ELP accounted for $13 \%$ of the total labeled bile pigment in the erythropoietin-treated rat, as compared to $16 \%$ in the controls. Underestimation of the circulating red cell mass may have accounted for the finding that during the plateau and late peak, ${ }^{14} \mathrm{C}$ incorporation into bilirubin was greater than anticipated 

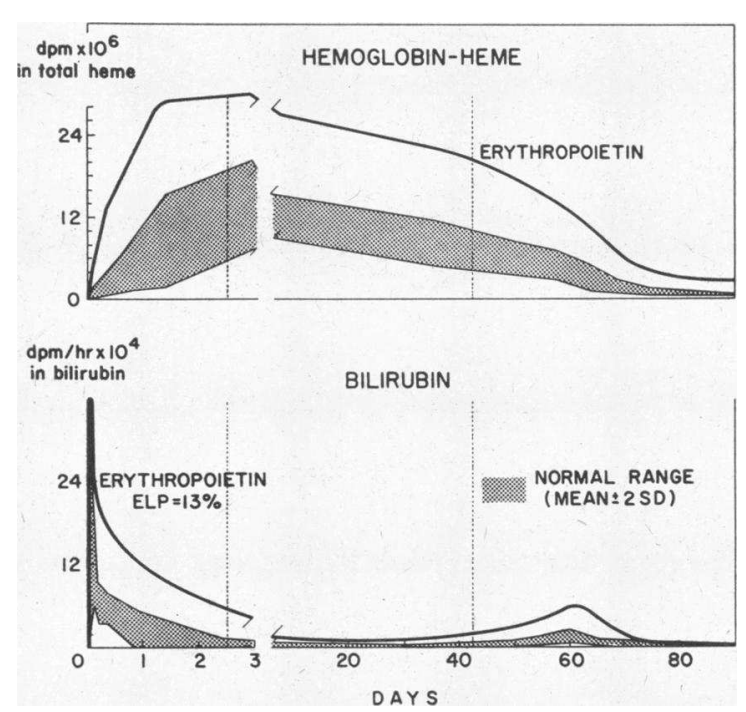

Fig. 7. Formation of Hemoglobin Heme $-{ }^{14} \mathrm{C}$ and BILIRUBIN $-{ }^{14} \mathrm{C}$ FROM GLYCINE-2 $-{ }^{14} \mathrm{C}$ IN PLETHORIC GUNN RAT TREATED WITH ERYTHROPOIETIN. Shaded area indicates values (mean $\pm 2 \mathrm{SD}$ ) in four Gunn rats with normal erythropoiesis.

from the radioactivity in circulating hemoglobin heme (Table I).

Gunn rats chronically exposed to hypoxia also showed increased incorporation of glycine- ${ }^{14} \mathrm{C}$ into circulating hemoglobin heme (Table I), comparable to that in the erythropoietin-treated animal. However, ELP formation was not enhanced, and indeed was lower than control values during the initial $3 \frac{1}{2}$ hours (Table I). It is possible that this unexpected finding was related to prolonged severe hypoxia ; all three animals died before completion of the experiments. It is noteworthy, however, that much shorter exposure to a comparable degree of hypoxia resulted in a significant increase in ELP formation.

The findings in two rats exposed to acute hypoxia are shown in Table III and Figure 8. Glycine- ${ }^{14} \mathrm{C}$ incorporation into circulating hemoglobin heme was greatly increased. Moreover, although the rate of labeled bilirubin formation during the early ELP phase remained normal, it was significantly increased between $3 \frac{1}{2}$ and 60 hours. This resulted in a different configuration of the ELP curve, with an apogee at approximately 8 hours and an unusually slow return toward base line (Figure 8).

Stimulation of erythropoiesis by repeated hemorrhage yielded similar findings, although fractional isotope incorporation into both heme and bilirubin was somewhat lower (Table III). As in acute hypoxia; the rate of bilirubin- ${ }^{14} \mathrm{C}$ production was comparable to that of control animals during the initial $3 \frac{1}{2}$ hours, but was enhanced during the late phase of the ELP (Figure 8).

Hypertransfusion suppressed erythropoiesis and resulted in a 20 - to 30 -fold reduction of glycine${ }^{14} \mathrm{C}$ incorporation into hemoglobin heme (Table III, Figure 9). Despite this decrease in erythropoiesis, little or no change was observed in ELP formation. The early phase was normal, and between $3 \frac{1}{2}$ and 60 hours, bilirubin- ${ }^{14} \mathrm{C}$ was produced at a normal or slightly reduced rate (Table III). The bone marrow of hypertransfused rats showed marked diminution of developing erythroid cells, rendering it highly improbable that there was a significant degree of ineffective erythropoiesis (5) after hypertransfusion.

$A L A-4-{ }^{14} C$ as precursor. The experiments in rats with stimulated or suppressed erythropoiesis confirmed the findings in animals with normal
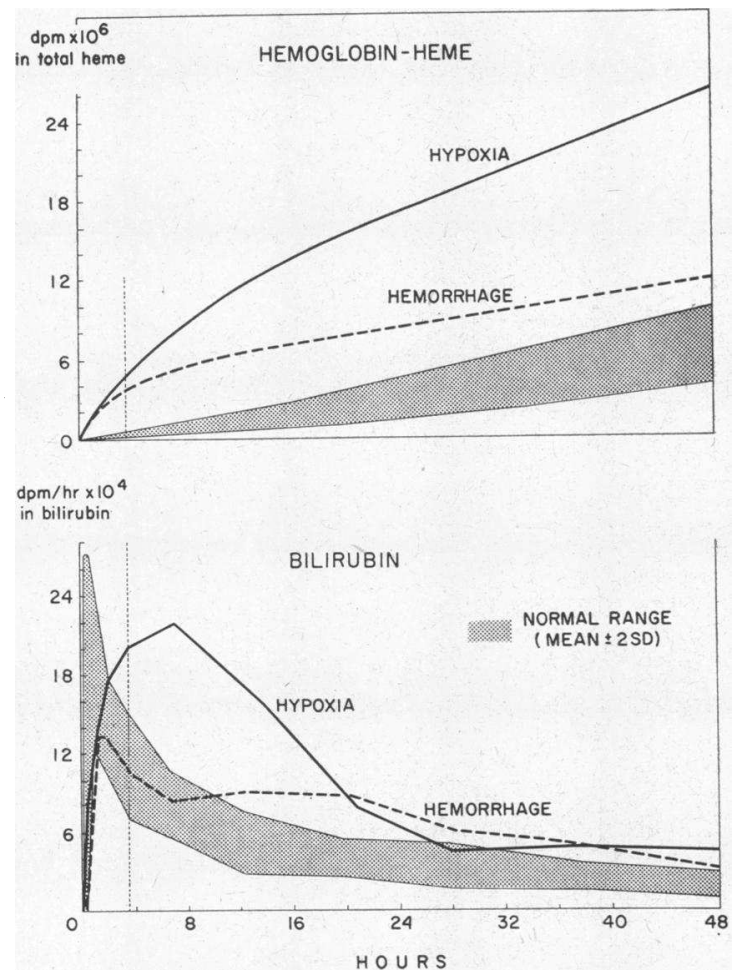

Fig. 8. EFFECT OF ERYThroid STIMUlation in Rats WITH EXTERNAL BILE DRAINAGE GIVEN GLYCINE-2 $-{ }^{14} \mathrm{C}$. Shaded area indicates values (mean $\pm 2 \mathrm{SD}$ ) in four animals with normal erythropoiesis. 


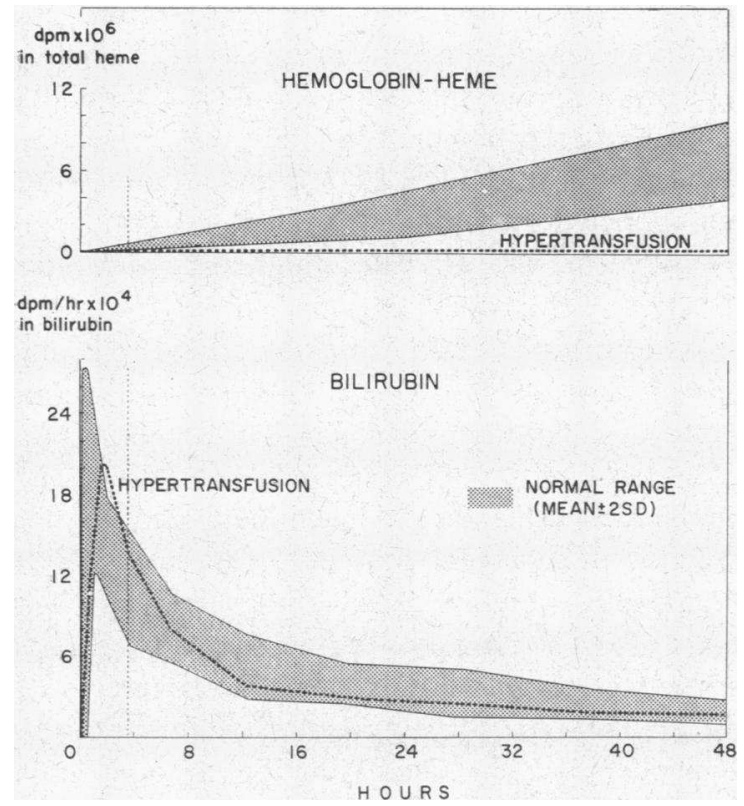

Fig. 9. EFFECT OF ERYTHROID SUPPRESSION IN HYPERTRANSFUSED RAT WITH EXTERNAL BILE DRAINAGE GIVEN GLYCINE-2- ${ }^{14} \mathrm{C}$. Shaded area indicates values (mean \pm 2 $\mathrm{SD})$ in four animals with normal erythropoiesis.

erythropoiesis that formation of labeled bile pigment from $\mathrm{ALA}-{ }^{14} \mathrm{C}$ is largely independent of red cell turnover. Acute hypoxia, hemorrhage, and hypertransfusion all failed to produce significant changes in ELP formation from ALA- ${ }^{14} \mathrm{C}$ (Table III). Minor differences in the ratio between the early and the late phase of ELP and in the configuration of the ELP curve (Figure 10) are probably of little significance. In hypoxic and bled rats there was a more gradual return of the curve toward base line, whereas in the hypertransfused rat this decline was somewhat accelerated, in comparison with the control animals. These changes

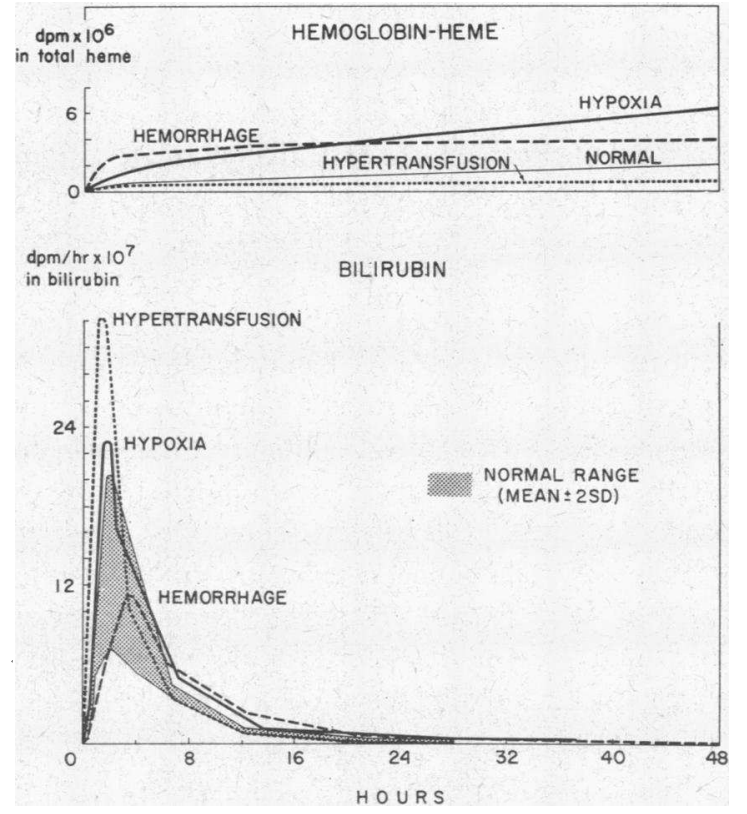

Fig. 10. EFFECTS OF ERYThroId StIMUlation AND SUPPRESSION IN RATS WITH EXTERNAL BILE DRAINAGE GIVEN ALA $-4-{ }^{14} \mathrm{C}$. Shaded area indicates values (mean $\pm 2 \mathrm{SD}$ ) in five animals with normal erythropoiesis.

were similar to the much more striking alterations observed in comparably treated animals given glycine- ${ }^{14} \mathrm{C}$ (Figures 8,9 ).

\section{Effect of drugs on ELP}

Intravenous infusion of allylisopropylacetamide in a Sprague-Dawley rat resulted in porphobilinogenuria, but it failed to increase significantly glycine- ${ }^{14} \mathrm{C}$ incorporation into ELP (Table IV). In rats fed griseofulvin for several weeks, no increase in fecal porphyrins was detectable, nor was ELP formation altered with either glycine- ${ }^{14} \mathrm{C}$ or ALA${ }^{14} \mathrm{C}$ as precursor.

TABLE IV

Effect of allylisopropylacetamide on fractional incorporation of glycine-2 $-{ }^{14} \mathrm{C}$ into bilirubin $-{ }^{14} \mathrm{C}$ in rat with external biliary drainage

\begin{tabular}{|c|c|c|c|}
\hline \multirow[b]{3}{*}{ Rats } & \multirow[b]{3}{*}{ Treatment } & \multirow{2}{*}{\multicolumn{2}{|c|}{$\begin{array}{c}\begin{array}{c}\text { Isotope incorporation into } \\
\text { bilirubin-14C }\end{array} \\
\text { ELP }\end{array}$}} \\
\hline & & & \\
\hline & & $\begin{array}{l}\text { Early phase } \\
0-3.5 \text { hours }\end{array}$ & $\begin{array}{l}\text { Late phase } \\
3.5-60 \text { hours }\end{array}$ \\
\hline \multirow{3}{*}{$\begin{array}{l}5 \text { normal Sprague-Dawley, } \\
\text { mean } \pm 2 \mathrm{SD} \\
1 \text { Sprague-Dawley }\end{array}$} & . & \multicolumn{2}{|l|}{$\%$} \\
\hline & None & $0.014 \pm 0.006$ & $0.087^{*}$ \\
\hline & Allylisopropylacetamide & 0.020 & 0.078 \\
\hline
\end{tabular}

* Average value from two rats. 


\section{Discussion}

Bilirubin is the major end product in the catabolism of hemoglobin and other heme-proteins (45). The rates of turnover of these chromoproteins vary widely, from a few hours for tryptophan pyrrolase (46), 1 to 2 days for catalase (47), to several months for myoglobin (48) and red cell hemoglobin $(2,3)$. Consequently, after administration of an isotopic precursor of heme, labeled bilirubin is produced at variable rates for many weeks, and complete assessment of bile pigment formation requires sample collections over extended periods of time. The intact, hyperbilirubinemic Gunn rats used in the present investigation permitted studies of unlimited duration. Experiments usually were terminated after 82 days because, in general agreement with previously reported findings (49-51), the average life-span of erythrocytes in the rat was found to be about 60 days, although some red cells were destroyed more rapidly in random fashion (Figures 2 and 4).

In addition to these long-term experiments in Gunn rats, short-term studies concerned only with ELP formation were performed in normal rats with external bile drainage. Except for small differences between the early and the late phases of ELP, the findings in these two groups of animals were similar (Figures 3 and 5), attesting to the validity of the experimental design in the longterm studies and permitting direct comparison of the results obtained with the two experimental models. This facilitated investigation of the ELP, since it eliminated the necessity for many shortterm experiments in Gunn rats, which withstand poorly manipulation of erythropoietic activity.

The methodologic limitations inherent in both experimental models are those commonly encountered in metabolic studies involving pulse labeling of a precursor pool (52), i.e., reutilization of label and inhomogeneous mixing of the injected isotope with endogenous precursor. The latter undoubtedly explains many of the findings with ALA- ${ }^{14} \mathrm{C}$ as precursor; this will be elaborated upon later. The problem of reutilization of labeled glycine for the continuous formation of labeled hemoglobin and bile pigment has been commented upon previously $(9,42)$. In the present studies, low-grade reutilization was suggested by persistence of radioactivity in hemoglobin heme af- ter day 82 (Figures 2 and 4). It is improbable that this was due to a minor population of erythrocytes with a prolonged life-span (42). The fall in the rate of bilirubin $-{ }^{14} \mathrm{C}$ formation to barely measurable levels after day 82 indicated that continued reincorporation of labeled precursor into bile pigment was of little significance for interpretation of the results.

Approximately $85 \%$ of the labeled bilirubin formed from glycine- ${ }^{14} \mathrm{C}$ was derived from degradation of labeled hemoglobin heme (Tables I and II). Most of this bile pigment was formed between 42 and 82 days, concomitant with the destruction of senescent red cells containing labeled hemoglobin (Figure 2). These findings were comparable to those in normal human subjects, in whom most isotopic stercobilin was excreted between 90 and 150 days after the administration of glycine- ${ }^{15} \mathrm{~N}(2,3)$, corresponding to an average red cell life span of 120 days. In addition, in the rats labeled bile pigment formed between $2 \frac{1}{2}$ and 42 days appeared to be derived largely from hemoglobin in erythrocytes destroyed at random (Figure 2, Table I).

Bilirubin $-{ }^{14} \mathrm{C}$ appearing during the initial 60 hours comprised the ELP and accounted for approximately $16 \%$ of the total labeled bile pigment formed from glycine- ${ }^{14} \mathrm{C}$ (Table II). This was similar to the values in normal human subjects obtained by radioassay of fecal stercobilin $(2,3)$. However, because of the time required for intestinal transit and because of enterohepatic recirculation of the bile pigment (21), fecal excretion of labeled stercobilin does not reflect the actual kinetics of ELP formation. In these human studies; maximal labeling of stercobilin was observed between 2 and 8 days $(2,3)$, whereas in the present animal experiments the rate of bilirubin- ${ }^{14} \mathrm{C}$ formation was highest between 1 and 2 hours after injection of the isotope (Figures 2 and $3)$.

The rapidity of this process made it seem unlikely that ELP is related to degradation of hemoglobin or heme formed during erythroid maturation in the bone marrow $(24,53)$. This was further supported by the finding that ELP formation during the initial $3 \frac{1}{2}$ hours generally was unaffected by stimulation or suppression of erythropoiesis (Figures 7-9, Tables I and III). The concept that this pigment fraction is not derived 
from hemoglobin of erythroid cells but is largely hepatic in origin was confirmed in experiments with isolated perfused rat liver (54).

In the Gunn rat treated with erythropoietin, labeled bilirubin production during the early phase of ELP appeared to be moderately increased ( $\mathrm{Ta}$ ble I, Figure 7). Since no similar increase occurred in any of the other animals with stimulated erythropoiesis (Tables I and III), the significance of this isolated observation is not clear. Possible although remote explanations include differences between erythropoietin and hypoxia or anemia in the mechanism of erythroid stimulation and a direct effect of the hormone on hepatic heme turnover. A more likely explanation is that the increase was spurious and related to the arbitrary division of the ELP into an early and late phase. Since on treatment with erythropoietin, formation of labeled bilirubin during the late phase of ELP was increased fourfold (Table I, Figure 7), some overlap with the early phase may have been unavoidable. This was evident also in the rats in which erythropoiesis was stimulated by hypoxia (Figure 8).

In the Gunn rats exposed to hypoxia for several weeks, the initial ELP component was significantly reduced, whereas the later phase appeared to be normal despite a marked increase in glycine- ${ }^{14} \mathrm{C}$ incorporation into hemoglobin heme accompanying the erythrocytosis (Table I). These findings are not readily explainable unless it is assumed that chronic hypoxia had a deleterious effect on the liver; all three animals died before completion of the experiment. By contrast, in rats rendered acutely hypoxic, the early component of ELP was normal, whereas the later phase was significantly increased (Table III). In both groups of animals, the dissociation between heightened erythroid activity and normal or diminished production of labeled bilirubin during the early phase of ELP is further evidence for the nonerythroid origin of this pigment fraction.

During the late phase of ELP, from $3 \frac{1}{2}$ to 60 hours after isotope administration, the rate of bilirubin ${ }^{14} \mathrm{C}$ formation gradually returned to the low, nearly constant values that prevailed over the subsequent 40 days (Figures 2, 3). Hypertransfusion, which resulted in marked suppression of erythropoiesis and hemoglobin synthesis, had little or no effect on ELP formation (Figure 9, Table
III), whereas erythroid stimulation was associated with a significant increase in bilirubin- ${ }^{14} \mathrm{C}$ production between $3 \frac{1}{2}$ and 60 hours (Figures 7, 8; Tables I, III). These observations suggested that aIthough under normal conditions formation of ELP is almost entirely independent of hemoglobin synthesis, this pigment fraction does contain a small erythropoietic component that lies buried in the descending limb of the curve. This component is so small that its abolition remains almost imperceptible on suppression of erythropoiesis (Figure 9), but it becomes significant on erythroid stimulation (Figures 7, 8).

In the Gunn rat treated chronically with erythropoietin, fractional glycine ${ }^{-14} \mathrm{C}$ incorporation into hemoglobin and bile pigment was enhanced, but the increase in ELP was proportionate to the rise in late bilirubin $-{ }^{14} \mathrm{C}$ production from hemoglobin in senescent erythrocytes (Figure 7, Table I). Thus, despite an absolute increase in ELP, this pigment fraction remained $13 \%$ of the total bilirubin- ${ }^{14} \mathrm{C}$ produced over the entire 82 days of the experiment (Table II). This observation helps to reconcile the divergent conclusions that were drawn from studies of ELP formation in individuals under erythropoietic stress $(14,15)$, in whom late bile pigment production was not assessed. The proportionate increase in ELP formation in response to erythropoietic stimulation is in marked contrast to the findings in hematological disorders with ineffective erythropoiesis (5), in which ELP may comprise the major fraction of the total labeled bile pigment $(4,6-9,11)$.

The precise mechanism by which bilirubin is produced in connection with the development of erythroid cells is unknown. Among the various explanations offered $(2,3,11,14,55-57)$, perhaps the most attractive is that it is derived from hemoglobin attached to (55) or included in (58) the nucleus that is extruded from the maturing erythroid cell. On the other hand, in ineffective erythropoiesis, it is tempting to assume that the disproportionate increase in ELP represents actual destruction of red cell precursors within the bone marrow.

Striking differences were observed in the labeling of bile pigment with glycine- ${ }^{14} \mathrm{C}$ and ALA${ }^{14} \mathrm{C}$ (Tables I-III). With glycine- ${ }^{14} \mathrm{C}$ fractional isotope incorporation into bilirubin during the entire 82 days of the experiment averaged $0.5 \%$ 
(Table I), and at least four-fifths of this labeled pigment was derived from breakdown of hemoglobin in senescent erythrocytes (Table II). By contrast, fractional incorporation of $\mathrm{ALA}-{ }^{14} \mathrm{C}$ into bilirubin was much larger, ranging from 13 to $43 \%$ (Table I), but less than one-hundredth of the labeled pigment appeared to arise from hemoglobin in circulating erythrocytes (Table I).

The configuration of the ELP curve observed with $\mathrm{ALA}-{ }^{14} \mathrm{C}$ was similar to that of the early component found with glycine- ${ }^{14} \mathrm{C}$ (Figures 2-5). With both precursors fractional incorporation into bilirubin during the initial $3 \frac{1}{2}$ hours was largely unaffected by either stimulation or suppression of erythropoiesis (Figures 8-10). However, with ALA $-{ }^{14} \mathrm{C}$ as precursor the maximal rate of bilirubin ${ }^{14} \mathrm{C}$ formation was approximately a thousand times higher than with glycine $-{ }^{14} \mathrm{C}$ (Figures $2,4)$, and the ELP accounted for 62 to $78 \%$ of the total bilirubin- ${ }^{14} \mathrm{C}$ produced (Table II); with glycine $-{ }^{14} \mathrm{C}$ as precursor, the corresponding figure was $16 \%$. These observations indicate that ALA${ }^{14} \mathrm{C}$ dramatically overemphasizes the metabolic pathways leading to bile pigment formation from nonhemoglobin sources. The conclusion that exogenous $\mathrm{ALA}-{ }^{14} \mathrm{C}$ preferentially labels nonhemoglobin sources of bilirubin has also been reached from short-term studies in man $(17,18)$ and in dogs $(19,59)$. The present experiments do not identify the anatomic site of this process. However, studies with isolated perfused rat liver (54) have shown that the liver is a major source of the bile pigment formed from $\mathrm{ALA}-{ }^{14} \mathrm{C}$, in that production of bilirubin $-{ }^{14} \mathrm{C}$ from $\mathrm{ALA}-{ }^{14} \mathrm{C}$ in vitro was comparable both in rate and magnitude to that observed in intact rats.

The finding that $\mathrm{ALA}-{ }^{14} \mathrm{C}$ is an efficient precursor of bile pigment formed in the liver but is poorly incorporated into hemoglobin heme suggests that exogenous ALA gains access to the sites of heme synthesis more easily in hepatic than in erythroid cells. ALA is a more direct precursor of heme than glycine (60), and in lysed avian erythrocytes ALA is incorporated into hemoglobin heme to a much greater extent than glycine (61). Similarly, in isolated perfused rat liver, $\mathrm{ALA}-{ }^{14} \mathrm{C}$ labels bilirubin a thousand times better than equimolar amounts of glycine (54). Although ALA is efficiently incorporated into hemoglobin by lysed reticulocytes, it is less well utilized by intact cells
(62), suggesting that erythroid cells are relatively impermeable to ALA (63). Therefore, administration of $\mathrm{ALA}-{ }^{14} \mathrm{C}$ to an intact animal would be expected to lead to increased labeling of heme in all sites except erythroid cells; paradoxically, these cells account for the major fraction of all heme synthesized.

With glycine ${ }^{14} \mathrm{C}$ as precursor, on the contrary, the pattern of bilirubin labeling appears to reflect more closely the physiologic relationship between turnover of heme compounds and formation of bile pigment. After pulse labeling in vivo, glycine ${ }^{-14} \mathrm{C}$ is rapidly and ubiquitously distributed in the body (64). Although it has been shown that completely homogeneous mixing of the isotope with the endogenous glycine pools cannot be achieved (65, 66), it appears a reasonable, if crude, approximation that there is uniform labeling of the amino acid in the major organs (65). The present investigation, like all previous isotopic studies of bile pigment metabolism, is based on this assumption.

The nature of the metabolic intermediates responsible for bilirubin formation from nonhemoglobin sources is unclear. Direct formation of bile pigment from pyrrolic precursors has not been definitely excluded (67). However, evidence has been reported $(19,59)$ that the ELP is related to the rapid turnover of one or several heme fractions in the liver and possibly in other organs. The concept that heme is an intermediate is supported by the finding that bilirubin $-{ }^{14} \mathrm{C}$ is produced rapidly and efficiently with hemin- ${ }^{14} \mathrm{C}$ as a precursor (Figure 6). The specific heme fractions that are involved in the rapid formation of ELP are unknown. Hepatic cytochrome $\mathrm{c}$ is an unlikely source, since this heme enzyme has a biologic halflife of 9.7 days (68). Hepatic catalase has a halflife of about 30 hours (47), but it has been suggested (47) that there may be a small fraction of catalase with a more rapid renewal rate. Similarly, tryptophan pyrrolase has a biologic halflife of 2.2 hours (46), and although its concentration in liver is small (69), its rate of turnover is rapid enough to qualify it as a potential contributor to ELP formation. The possible role of other hepatic heme enzymes, including the microsomal cytochrome P 450 (70), is difficult to assess because their turnover rates are still unknown (71).

It should be noted that during the plateau and 
late peak intervals, production of labeled bilirubin from $\mathrm{ALA}-{ }^{14} \mathrm{C}$ continued at rates far in excess of those expected from breakdown of labeled hemoglobin heme (Tables I, II). This suggests that in the liver and probably in other organs $(19,59)$, ALA $-{ }^{14} \mathrm{C}$ serves as precursor for a variety of heme compounds encompassing a wide spectrum of turnover rates.

It has been reported that heme synthesis in the liver is increased in experimental porphyria (72-75). However, the results in Table IV show that AIA did not significantly alter the rate and magnitude of ELP formation, suggesting that this porphyrinogenic substance is selective in its effect on hepatic heme compounds and spares the heme precursors of ELP. A similar selectivity has been observed in the synthesis of hepatic catalase, which is inhibited by Sedomid and AIA (72), whereas cytochrome $\mathrm{c}$ remains unaffected (72). The ELP was also unchanged in rats fed griseofulvin, but these animals failed to show an increase in porphyrin excretion.

The present findings concerning the sites and kinetics of ELP formation are at variance with those of most previous studies in man $(13,14,17$, $18)$ and dogs $(16,19)$, which suggested that a major portion of the ELP formed from isotopic glycine is related to erythropoiesis. This discrepancy may be due partly to species variation, but it probably also reflects the difference in methodologic approach. When bile pigment production was assessed in anicteric subjects from the radioactivity of serum bilirubin $(17,18)$, two bilirubin${ }^{14} \mathrm{C}$ peaks were observed with glycine- ${ }^{14} \mathrm{C}$, one between 12 and 24 hours and a second between 3 and 5 days; the later peak appeared to be related to red cell formation. However, bilirubin specific activity in the bile collected concomitantly was much lower than that in the plasma, and the biphasic pattern was absent (18). With $\mathrm{ALA}-{ }^{14} \mathrm{C}$, on the other hand, ELP formation occurred much more rapidly and was maximal at about $1 \frac{1}{2}$ hours $(17,18)$, in conformity with the present findings. By contrast, in the current study, labeled bilirubin formation was maximal at 1 to 2 hours with both glycine $-{ }^{14} \mathrm{C}$ and $\mathrm{ALA}-{ }^{14} \mathrm{C}$ (Figures $2-5$ ). Moreover, the kinetics of bilirubin- ${ }^{14} \mathrm{C}$ formation were comparable whether measured in the bile or in the pigment pool of Gunn rats (Figures 3, 5).

\section{Summary}

New techniques were developed for accurate assessment of the kinetics of bile pigment formation in intact hyperbilirubinemic Gunn rats over extended periods of time. In addition, formation of early labeled pigment (ELP) was studied in normal rats with external bile drainage. The findings in these two experimental models were similar and form the basis for the following conclusions :

1) With glycine- $2-{ }^{14} \mathrm{C}$ as precursor, over $80 \%$ of the total bilirubin $-{ }^{14} \mathrm{C}$ produced was derived from labeled hemoglobin in circulating red cells. Most of the labeled bile pigment was formed between 42 and 82 days after isotope administration and originated from destruction of senescent erythrocytes with an average life-span of approximately 60 days. Random destruction of labeled red cells between $2 \frac{1}{2}$ and 42 days served as an additional source of bilirubin $-{ }^{14} \mathrm{C}$ formation.

2) Incorporation of glycine- ${ }^{14} \mathrm{C}$ into $\mathrm{ELP}$ accounted for $16 \%$ of the total labeled bile pigment produced over the entire 82 days of the experiments. The rate of bilirubin $-{ }^{14} \mathrm{C}$ formation was maximal 1 to 2 hours after isotope administration and then fell off asymptotically over the ensuing 60 hours. The early phase of ELP appeared to be virtually independent of erythropoiesis, and its kinetics resembled those of labeled pigment formation by isolated perfused rat liver. The late phase of ELP, extending from $3 \frac{1}{2}$ to 60 hours, also was derived largely from nonhemoglobin sources, but it did contain a very small erythropoietic component that became discernible on erythroid stimulation.

3) Chronic stimulation of red cell production resulted in a marked increase of the second phase of ELP accompanied by a commensurate rise in late bilirubin ${ }^{14} \mathrm{C}$ formation from labeled erythrocytes in the circulation. Consequently, the quantitative relationship between early and late bile pigment formation was similar in physiologic and in accelerated erythropoiesis, with the ELP comprising 13 to $16 \%$ of the total bilirubin $-{ }^{14} \mathrm{C}$ produced.

4) With $\delta$-aminolevulinic acid (ALA) $-{ }^{14} \mathrm{C}$ as precursor, the early phase of ELP was strikingly increased and was comparable to labeled pigment formation from ALA in isolated perfused rat liver. 
Moreover, nonhemoglobin sources labeled by ALA $-{ }^{14} \mathrm{C}$ continued to produce bilirubin $-{ }^{14} \mathrm{C}$ during the entire 82 days of the experiments. Since fractional isotope incorporation into red cell hemoglobin heme was small, more than $99 \%$ of the total labeled bile pigment formed from $\mathrm{ALA}-{ }^{14} \mathrm{C}$ originated from sources other than hemoglobin in erythroid cells.

5) The findings emphasize the significance of bile pigment formation from nonerythroid sources, which in the normal rat account for almost the entire ELP. With $\mathrm{ALA}-{ }^{14} \mathrm{C}$ as precursor, these metabolic pathways are dramatically overemphasized, whereas with glycine- ${ }^{14} \mathrm{C}$ bilirubin labeling appears to reflect more closely the physiologic relationship between the turnover of hemoglobin and other heme compounds and the formation of bile pigment.

\section{Appendix}

Computation of the rate of bilirubin $-{ }^{14} \mathrm{C}$ formation in Gunn rats

We made the following assumptions:

a) The bilirubin pool and its rate of turnover remain constant during the experiment. The validity of this assumption was established in six Gunn rats by determining these values on two occasions 3 to $8 \frac{1}{2}$ months apart: The rats were injected with bilirubin $-{ }^{14} \mathrm{C}$, and the amount of labeled pigment in the pool was measured at various times ( $t$ ) (23). In all animals, disappearance of bilirubin- ${ }^{14} \mathrm{C}$ conformed to a first-order reaction, i.e., an expression of the form $\mathrm{Ce}^{-\mathrm{kt}}$, where $\mathrm{k}$ is the slope of the regression line when plotted on semilogarithmic paper.

b) Bilirubin $-{ }^{14} \mathrm{C}$ formed is instantly mixed in the pigment pool. This assumption is an oversimplification in that obviously a finite time is required for mixing of newly formed bilirubin with the pigment pool. However, in preliminary experiments it was found that after a single intravenous injection of a few micrograms of bilirubin $-{ }^{14} \mathrm{C}$, isotope disappearance approximated a single exponential rate within 20 minutes. Thus, the error introduced by assuming instant pigment mixing appeared to be insignificant for computation of the production rate of bilirubin- ${ }^{14} \mathrm{C}$.

c) A further restrictive assumption has to be made because of the limited number of serum samples available for analysis. After administration of an isotopic precursor, let $f(t)$ be the rate at which bilirubin $-{ }^{14} \mathrm{C}$ enters the pigment pool at time $t$, and let $F(\tau)$ be the amount of labeled bilirubin present in the pool at time $\tau$. With the above assumptions, it follows that

$$
F(\tau)=\int_{0}^{\tau} f(t) e^{-k(\tau-t)} d t,
$$

where $\mathrm{k}$ is the turnover rate discussed under $a$ ). Because the number of blood samples taken over the 82 days of the study was limited to 11 to $13, f(t)$ could be continuously observed. This required an assumption restricting the nature of $f(t)$, and $f(t)$ was therefore approximated by a step function. We assumed that $f(t)$ is constant between any two observations of $F$. Independent cross validation of this assumption was provided by the experimental finding that the rate of bilirubin $-{ }^{14} \mathrm{C}$ production in rats with an external bile fistula was very similar to that computed in Gunn rats (Figures 3 and 5).

These assumptions were used to formulate a step function approximation to $f(t)$ in the following manner. It is desirable to find a constant, a, so that bilirubin $-{ }^{14} \mathrm{C}$ production at constant rate a between times $\delta$ and $\tau$ (the times of successive observations of $F$ ) will account for the observed change in $\mathrm{F}$ values. We compute:

$$
\begin{aligned}
& \mathrm{F}(\tau)-\mathrm{F}(\sigma)=\int_{0}^{\tau} \mathrm{f}(\mathrm{t}) \mathrm{e}^{-\mathrm{k}(\tau-\mathrm{t})} \mathrm{dt}-\int_{0}^{\sigma} \mathrm{f}(\mathrm{t}) \mathrm{e}^{-\mathrm{k}(\sigma-\mathrm{t})} \mathrm{dt} \\
& =\mathrm{e}^{-\mathrm{k} \tau} \int_{0}^{\tau} \mathrm{f}(\mathrm{t}) \mathrm{e}^{\mathrm{kt}} \mathrm{dt}-\mathrm{e}^{-\mathrm{k} \sigma} \int_{0}^{\sigma} \mathrm{f}(\mathrm{t}) \mathrm{e}^{\mathrm{kt}} \mathrm{dt} \\
& =\left(\mathrm{e}^{-\mathrm{k} \tau}-\mathrm{e}^{-\mathrm{k} \sigma}\right) \int_{0}^{\sigma} \mathrm{f}(\mathrm{t}) \mathrm{e}^{\mathrm{kt}} \mathrm{dt}+\mathrm{e}^{-\mathrm{k} \tau} \int_{\sigma}^{\tau} \mathrm{f}(\mathrm{t}) \mathrm{e}^{\mathrm{kt}} \mathrm{dt} \\
& =\left(\mathrm{e}^{-\mathrm{k}(\tau-\sigma)}-1\right) \mathrm{F}(\sigma)+\mathrm{e}^{-\mathrm{k} \tau} \int_{\sigma}^{\tau} \mathrm{f}(\mathrm{t}) \mathrm{e}^{\mathrm{kt}} \mathrm{dt} .
\end{aligned}
$$

Since between $\delta$ and $\tau, \mathrm{f}(\mathrm{t})$ has the constant value a, it follows that

$$
\int_{\sigma}^{\tau} \mathrm{f}(\mathrm{t}) \mathrm{e}^{\mathrm{kt}} \mathrm{dt}=\int_{\sigma}^{\tau} \mathrm{a} \mathrm{e}^{\mathrm{kt}}=\frac{\mathrm{a}}{\mathrm{k}}\left(\mathrm{e}^{\mathrm{k} \tau}-\mathrm{e}^{\mathrm{k} \sigma}\right) .
$$

This equation can be solved for a, yielding

$$
\mathrm{a}=\left[1 /\left(\mathrm{e}^{\mathrm{k} \tau}-\mathrm{e}^{\mathrm{k} \sigma}\right)\right] \cdot\left[\mathrm{e}^{\mathrm{k} \tau} \mathrm{F}(\tau)-\mathrm{e}^{\mathrm{k} \tau} \mathrm{F}(\sigma)\right] .
$$

In the experiments, $a$ is expressed as disintegrations per minute in bilirubin- ${ }^{14} \mathrm{C}$ formed per hour.

\section{References}

1. Robinson, S. H., M. Tsong, B. W. Brown, and R. Schmid. Sites and kinetics of bile pigment formation in the rat (abstract). J. Lab. clin. Med. 1965, 66, 1015.

2. London, I. M., R. West, D. Shemin, and D. Rittenberg. On the origin of bile pigment in normal man. J. biol. Chem. 1950, 184, 351.

3. Gray, C. H., A. Neuberger, and P. H. A. Sneath. Studies in congenital porphyria. 2. Incorporation of ${ }^{15} \mathrm{~N}$ in the stercobilin in the normal and in the porphyric. Biochem. J. 1950, 47, 87.

4. Israels, L. G., and A. Zipursky. Primary shunt. hyperbilirubinaemia. Nature (Lond.) 1962, 193, 73.

5. Giblett, E. R., D. H. Coleman, G. Pirzio-Biroli, D. M. Donohue, A. G. Motulsky, and C. A. Finch. Erythrokinetics: quantitative measurement of red cell production and destruction in normal subjects and patients with anemia. Blood 1956, 11, 291.

6. London, I. M., and R. West. The formation of bilepigment in pernicious anemia. J. biol. Chem. 1950, $184,359$. 
7. London, I. M., R. West, D. Shemin, and D. Rittenberg. Porphyrin formation and hemoglobin metabolism in congenital porphyria. J. biol. Chem. 1950, 184, 365.

8. Grinstein, M., R. M. Bannerman, J. D. Vavra, and C. V. Moore. Hemoglobin metabolism in thalassemia : in vivo studies. Amer. J. Med. 1960, 29, 18.

9. Robinson, S., T. Vanier, J. F. Desforges, and R. Schmid. Jaundice in thalassemia minor. A consequence of "ineffective erythropoiesis." New Engl. J. Med. 1962, 267, 523.

10. James, G. W. III, and L. D. Abbott, Jr. Stercobilin $\mathrm{N}^{15}$ excretion in refractory anemia. Trans. Amer. clin. climat. Ass. 1961, 73, 110.

11. Berendsohn, S., J. Lowman, D. Sundberg, and C. J. Watson. Idiopathic dyserythropoietic jaundice. Blood 1964, 24, 1.

12. Gray, C. H., A. Kulczycka, D. C. Nicholson, I. A. Magnus, and C. Rimington. Isotope studies on a case of erythropoietic protoporphyria. Clin. Sci. 1964, 26, 7.

13. Barrett, P. V. D., M. J. Cline, and N. I. Berlin. The association of the urobilin "early peak" and erythropoiesis (abstract). Clin. Res. 1964, 12, 108.

14. Gray, C. H., and J. J. Scott. The effect of haemorrhage on the incorporation of $\left[\alpha{ }^{14} \mathrm{C}\right]$ glycine into stercobilin. Biochem. J. 1959, 71, 38.

15. James, G. W. III. Stercobilin and hematopoiesis. Amer. J. clin. Nutr. 1955, 3, 64.

16. Israels, L. G., J. Skanderbeg, H. Guyda, W. Zingg, and A. Zipursky. A study of the early-labelled fraction of bile pigment: the effect of altering erythropoiesis on the incorporation of $\left[2-{ }^{14} \mathrm{C}\right] \mathrm{gly}-$ cine into haem and bilirubin. Brit. J. Haemat. 1963, 9, 50.

17. Israels, L. G., T. Yamamoto, J. Skanderbeg, and A. Zipursky. Shunt bilirubin: evidence for two components. Science 1963, 139, 1054.

18. Yamamoto, T., J. Skanderbeg, A. Zipursky, and L. G. Israels. The early appearing bilirubin: evidence for two components. J. clin. Invest. 1965, 44, 31 .

19. Schwartz, S., G. Ibrahim, and C. J. Watson. The contribution of non-hemoglobin hemes to the early labeling of bile bilirubin (abstract). J. Lab. clin. Med. 1964, 64, 1003.

20. Watson, C. J. Recent studies of the urobilin problem. J. clin. Path. 1963, 16, 1.

21. Lester, R., W. Schumer, and R. Schmid. Intestinal absorption of bile pigments. IV. Urobilinogen absorption in man. New Engl. J. Med. 1965, 272, 939.

22. Gunn, C. H. Hereditary acholuric jaundice in a new mutant strain of rats. J. Hered. 1938, 29, 137.

23. Schmid, R., and L. Hammaker. Metabolism and disposition of $\mathrm{C}^{\mathbf{1 4}}$-bilirubin in congenital nonhemolytic jaundice. J. clin. Invest. 1963, 42, 1720.

24. Robinson, S. H., and R. Schmid. The relation of erythropoiesis to bile pigment formation. Medicine (Baltimore) 1964, 43, 667.
25. Little, J. R., G. Brecher, T. Bradley, and S. Rose. Determination of lymphocyte turnover by continuous infusion of $\mathrm{H}^{3}$ thymidine. Blood 1962, 19, 236.

26. Malloy, H. T., and K. A. Evelyn. The determination of bilirubin with the photoelectric colorimeter. J. biol. Chem. 1937, 119, 481.

27. Weber, A. Ph., and L. Schalm. Quantitative separation and determination of bilirubin and conjugated bilirubin in human serum. Clin. chim. Acta 1962, 7, 805.

28. Ostrow, J. D., L. Hammaker, and R. Schmid. The preparation of crystalline bilirubin- $\mathrm{C}^{\mathbf{1 4}}$. J. clin. Invest. 1961, 40, 1442.

29. Keene, W. R., and J. H. Jandl. Studies of the retizuloendothelial mass and sequestering function of rat bone marrow. Blood 1965, 26, 157.

30. Brecher, G. New methylene blue as a reticulocyte stain. Amer. J. clin. Path. 1949, 19, 895.

31. Crosby, W. H., J. I. Munn, and F. W. Furth. Standardizing a method for clinical hemoglobinometry. U. S. armed Forces med. J. 1954, 5, 693.

32. Labbe, R. F., and G. Nishida. A new method of hemin isolation. Biochim. biophys. Acta (Amst.) 1957, 26, 437.

33. Shemin, D., I. M. London, and D. Rittenberg. The synthesis of protoporphyrin in vitro by red blood cells of the duck. J. biol. Chem. 1950, 183, 757.

34. Oliverio, V. T., C. Denham, and J. D. Davidson. Oxygen flask combustion in determination of $\mathrm{C}^{14}$ and $\mathrm{H}^{3}$ in biological materials. Analyt. Biochem. 1962, 4, 188.

35. General Statistics, Monroe Calculating Machine Methods. Orange, N. J., Monroe International, 1964, p. 28.

36. Keighley, G., D. Hammond, and P. H. Lowy. The sustained action of erythropoietin injected repeatedly into rats and mice. Blood 1964, 23, 99.

37. Rimington, C., and D. J. Cripps. Biochemical and fluorescence-microscopy screening-tests for erythropoietic protoporphyria. Lancet 1965, 1, 624.

38. Watson, C. J., and S. Schwartz. A simple test for urinary porphobilinogen. Proc. Soc. exp. Biol. (N. Y.) 1941, 47, 393.

39. Gurney, C. W. Personal communication.

40. Darian Smith, I., and W. J. Simmonds. The changes in cardiac output, right atrial pressure and blood volume in haemorrhagic anaemias in unanaesthetized rabbits. Aust. J. exp. Biol. med Sci. 1954, 32, 241.

41. Whyte, H. M. Plasma and blood volume in anaemia and the effect of transfusion. Aust. Ann. Med. 1956, 5, 192.

42. Berlin, N. I., C. Hewitt, and C. Lotz. Hippuric acid synthesis in man after the administration of $\left[\alpha-{ }^{14} \mathrm{C}\right]$ glycine. Biochem. J. 1954, 58, 498.

43. Berlin, N. I., A. Neuberger, and J. J. Scott. The metabolism of $\delta$-aminolaevulic acid. 2. Normal pathways, studied with the aid of ${ }^{14} \mathrm{C}$. Biochem. J. 1956, 64, 90. 
44. Snyder, A. L., and R. Schmid. The conversion of hematin to bile pigment in the rat. J. Lab. clin. Med. 1965, 65, 817.

45. Lemberg, R., and J. W. Legge. Hematin Compounds and Bile Pigments. Their Constitution, Metabolism and Function. New York, Interscience, 1949, p. 544.

46. Schimke, R. T., E. W. Sweeney, and C. M. Berlin. The roles of synthesis and degradation in the control of rat liver tryptophan pyrrolase. J. biol. Chem. 1965, 240, 322.

47. Price, V. E., W. R. Sterling, V. A. Tarantola, R. W. Hartley, Jr., and M. Rechcigl, Jr. The kinetics of catalase synthesis and destruction in vivo. J. biol. Chem. 1962, 237, 3468.

48. Theorell, H., M. Béznak, R. Bonnichsen, K.-G. Paul, and A. A keson. On the distribution of injected radioactive iron in guinea pigs and its rate of appearance in some hemoproteins and ferritin. Acta chem. scand. 1951, 5, 445.

49. Berlin, N. I., L. M. Meyers, and M. Lazarus. Life span of the rat red blood cell as determined by glycine-2- $\mathrm{C}^{14}$. Amer. J. Physiol. 1951, 165, 565.

50. Belcher, E. H., and E. B. Harriss. Studies of red cell life span in the rat. J. Physiol. (Lond.) 1959, 146, 217.

51. Hughes Jones, N. C., and B. Cheney. The use of ${ }^{51} \mathrm{Cr}$ and ${ }^{59} \mathrm{Fe}$ as red cell labels to determine the fate of normal erythrocytes in the rat. Clin. Sci. 1961, $20,323$.

52. Solomon, A. K. Equations for tracer experiments. J. clin. Invest. 1949, 28, 1927.

53. Ostrow, J. D., J. H. Jandl, and R. Schmid. The formation of bilirubin from hemoglobin in vivo. J. clin. Invest. 1962, 41, 1628.

54. Robinson, S. H., C. A. Owen, Jr., E. V. Flock, and R. Schmid. Bilirubin formation in the liver from nonhemoglobin sources. Experiments with isolated, perfused rat liver. Blood 1965, 26, 823.

55. Bessis, M., J. Breton-Gorius, and J.-P. Thiery. Rôle possible de l'hémoglobine accompagnant le noyau des érythroblastes dans l'origine de la stercobiline éliminée précocement. C. R. Acad. Sci. (Paris) 1961, 252, 2300.

56. Fessas, P. Inclusions of hemoglobin in erythroblasts and erythrocytes of thalassemia. Blood 1963, 21, 21.

57. Berendes, M. The proportion of reticulocytes in the erythrocytes of the spleen as compared with those of circulating blood, with special reference to hemolytic states. Blood 1959, 14, 558.

58. Granick, S., and R. D. Levere. Heme synthesis in erythroid cells in Progress in Hematology, C. V. Moore and E. B. Brown, Eds. New York, Grune \& Stratton, 1964, vol. 4, pp. 24-26.

59. Schwartz, S., and R. Cardinal. Incorporation of ALA-C ${ }^{14}$ into dog tissue hemes. Fed. Proc. 1965, $24,485$.
60 Shemin, D., and C. S. Russell. $\delta$-Aminolevulinic acid; its role in the biosynthesis of porphyrins and purines. J. Amer. Chem. Soc. 1953, 75, 4873.

61. Shemin, D. The succinate-glycine cycle: the role of $\delta$-aminolevulinic acid in porphyrin synthesis in Ciba Foundation Symposium on Porphyrin Biosynthesis and Metabolism, G. E. W. Wolstenholme and E. C. P. Millar, Eds. London, J. \& A. Churchill, 1955, p. 4.

62. Vavra, J. D., V. K. Mayer, and C. V. Moore. In vitro heme synthesis by human blood: abnormal heme synthesis in thalassemia minor. J. Lab. clin. Med. 1964, 63, 736.

63. Scott, J. J. The metabolism of $\delta$-aminolaevulinic acid in Ciba Foundation Symposium on Porphyrin Biosynthesis and Metabolism, G. E. W. Wolstenholme and E. C. P. Millar, Eds. London, J. \& A. Churchill, 1955, p. 43.

64. Watts, R. W. E., and J. C. Crawhall. The first glycine metabolic pool in man. Biochem. J. 1959, $73,277$.

65. Neuberger, A. Aspects of the metabolism of glycine and of porphyrins. Biochem. J. 1961, 78, 1.

66. Garfinkel, D., and A. Lajtha. A metabolic inhomogeneity of glycine in vivo. I. Experimental determination. J. biol. Chem. 1963, 238, 2429.

67. Watson, C. J. The continuing challenge of hemoglobin and bile pigment metabolism. Ann. intern. Med. 1965, 63, 931.

68. Fletscher, M. J., and D. R. Sanadi. Turnover of rat-liver mitochondria. Biochim. biophys. Acta (Amst.) 1961, 51, 356.

69. Schimke, R. T., E. W. Sweeney, and C. M. Berlin. Studies of the stability in vivo and in vitro of rat liver tryptophan pyrrolase. J. biol. Chem. 1965, 240, 4609.

70. Klingenberg, M. Pigments of rat liver microsomes. Arch. Biochem. 1958, 75, 376.

71. Marver, H. S., D. P. Tschudy, M. G. Perlroth, and A. Collins. $\delta$-Aminolevulinic acid synthetase. I. Studies in liver homogenates. J. biol. Chem. 1966, 241, 2803.

72. Schmid, R., J. F. Figen, and S. Schwartz. Experimental porphyria. IV. Studies of liver catalase and other heme enzymes in Sedormid porphyria. J. biol. Chem. 1955, 217, 263.

73. Labbe, R. F., Y. Hanawa, and F. I. Lottsfeldt. Heme and fatty acid biosynthesis in experimental porphyria. Arch. Biochem. 1961, 92, 373.

74. De Matteis, F., and C. Rimington. Disturbance of porphyrin metabolism caused by griseofulvin in mice. Brit. J. Derm. 1963, 75, 91.

75. Labbe, R. F., T. Kurumada, and J. Onisawa. The role of succinyl-CoA synthetase in the control of heme biosynthesis. Biochim. biophys. Acta (Amst.) 1965, 111, 403. 